\title{
Diabetes, oxidative stress and therapeutic strategies
}

\author{
Luc Rochette, Marianne Zeller, Yves Cottin and Catherine Vergely \\ Laboratoire de Physiopathologie et Pharmacologie Cardio-Métaboliques, INSERM UMR866, \\ Université de Bourgogne, Facultés de Médecine et Pharmacie, 7 Boulevard Jeanne d'Arc, \\ 21079 DIJON, France.
}

$\bowtie$ Correspondence should be addressed to Pr Luc Rochette

Laboratoire de Physiopathologie et Pharmacologie Cardio-Métaboliques, INSERM UMR866, Université de Bourgogne, Facultés de Médecine et Pharmacie, 7 Boulevard Jeanne d'Arc, 21079 DIJON, France

Phone: +33380393291

Fax: +33 380393293

Email: luc.rochette@u-bourgogne.fr

Short running title: Oxidative stress and diabetes 


\begin{abstract}
Diabetes has emerged as a major threat to health worldwide. The exact mechanisms underlying the disease are unknown; however, there is growing evidence that excess generation of reactive oxygen species (ROS), largely due to hyperglycemia, causes oxidative stress in a variety of tissues. Oxidative stress results from either an increase in free radical production, or a decrease in endogenous antioxidant defenses, or both. ROS and reactive nitrogen species (RNS) are products of cellular metabolism and are well recognized for their dual role as both deleterious and beneficial species. In type 2 diabetic patients, oxidative stress is closely associated with chronic inflammation. Multiple signaling pathways contribute to the adverse effects of glucotoxicity on cellular functions. There are many endogenous factors (antioxidants, vitamins, antioxidant enzymes, metal ion chelators) that can serve as endogenous modulators of the production and action of ROS. Clinical trials that investigated the effect of antioxidant vitamins on the progression of diabetic complications gave negative or inconclusive results. This lack of efficacy might also result from the fact that they were administered at a time when irreversible alterations in the redox status are already under way. Another strategy to modulate oxidative stress is to exploit the pleiotropic properties of drugs directed primarily at other targets and thus acting as indirect antioxidants. It appears important to develop new compounds that target key vascular ROS producing enzymes and mimic endogenous antioxidants. This strategy might prove clinically relevant in preventing the development and/or retarding the progression of diabetes associated with vascular diseases.
\end{abstract}

Key words: diabetes, oxidative stress, reactive oxygen species, signaling pathways, therapeutics 


\section{Introduction}

Diabetes mellitus is a chronic disease characterized by elevated blood sugar levels resulting from either a lack of insulin production or resistance to insulin. About 230 million people worldwide had diabetes in 2010. The global figure of people with diabetes is projected to increase to 333 million in 2025, and 430 million in 2030 [1]. As the prevalence of diabetes has risen to epidemic proportions worldwide, the vascular complications of diabetes have now become one of the most challenging health problems. A relatively small proportion $(10 \%)$ of patients suffering from diabetes mellitus has type 1 or insulin-dependent diabetes. However, the majority of diabetes patients are not insulin-dependent and able, at least initially, to produce the hormone. This type of diabetes mellitus (DM) is termed type 2 diabetes. Insulin resistance (IR) is a fundamental aspect of the etiology of type 2 diabetes. Irrespective of the etiology, subjects with diabetes have an increased risk of ischemic heart disease, atherosclerosis and nephropathy [2].

Obesity, which is a major public health concern worldwide, increases the risk of type-2 diabetes [3]. Early in the development of type-2 diabetes, IR requires the production of extra insulin to maintain normal blood glucose levels. In the majority of obese individuals, hyperinsulinemia can occur with an increase in beta-cell mass, which facilitates the increased production of insulin. As a result, these individuals do not develop diabetes. However, approximately one third of obese individuals exhibit a decrease in beta-cell mass caused by beta-cell apoptosis, which renders these individuals unable to compensate for their IR-state and the resulting hyperglycemia, leading to a diagnosis of type 2 diabetes. Thus, type 2 diabetes is caused by a combination of IR coupled with insufficient production of insulin to overcome the IR [4]. 
Endothelial dysfunction underlies both micro- and macrovascular complications of diabetes. Microvascular disease leads to diabetic retinopathy, nephropathy and neuropathy. Oxidative stress plays a key role in the pathogenesis of micro- and macrovascular diabetic complications. The increased oxidative stress in subjects with type 2 diabetes is a consequence of several abnormalities, including hyperglycemia, IR, inflammation and dyslipidemia [5]. Endothelial function is important for the homeostasis of the body and its dysfunction is associated with several pathophysiological conditions, including atherosclerosis, hypertension and diabetes. Patients with diabetes invariably show an impairment of endothelium-dependent vasodilation [6]. These dysfunctions contribute to mitochondrial superoxide overproduction in endothelial cells. The purpose of the present review is to consider the opportunities presented by currently used therapeutic agents which possess antioxidant properties, as well as those offered by new potential antioxidant substances.

Diabetes impact on the different steps in the pathogenesis of cardiovascular diseases (CVD) [7-9]. Obesity and IR in patients suffering from diabetes are associated with a chronic systemic inflammation, characterized by an increased expression of inflammatory markers. Multiple stimuli are among the most common causes of myocardial inflammation in cardiomyopathies in diabetic patients [10-12]. Diabetes is an established major factor of poor prognosis after an acute coronary syndrome (ACS). Abnormal glycemic regulation is more common than normal regulation in patients presenting with acute coronary syndrome. High blood glucose at admission, whether fasting or not, is associated with worse outcome [increased mortality and development of severe heart failure] in patients with acute coronary syndrome. The prognostic value of glycaemia applies to both short and long term outcomes. However, fasting glycaemia is a more powerful predictor than glucose levels upon admission 
for short term outcome after myocardial infarction. The mechanisms by which hyperglycemia worsens cardiovascular prognosis, in particular as regards left ventricular dysfunction and acute coronary syndrome, are not fully understood. Such patients are predisposed to a proinflammatory, prothrombotic state, which may lead to plaque rupture. Stress hyperglycemia may be a marker of extensive cardiac damage, reflecting a surge of stress hormones such as catecholamines and cortisol that contribute to IR and affect fatty acid and glucose homeostasis [13]. Intravenous insulin therapy is used in diabetic patients at the acute phase of coronary syndrome. Hyperglycemia in diabetic patients is a powerful predictive factor for patient outcome as it is associated with a doubling of in-hospital mortality and poor long-term prognosis. In non-diabetic patients, even mild hyperglycemia in the setting of ACS is also a predictive factor of in-hospital mortality. Moreover, impaired fasting glucose is not only an independent factor of mortality for coronary patients, but is associated with a doubling of the risk of in-hospital mortality in the setting of ACS [14, 15]. After myocardial infarction, diabetic patients have a significantly higher risk of heart failure and cardiogenic shock. Circulating B-type natriuretic peptide (BNP) and its prohormone (NT-proBNP) levels are used for screening, diagnosis, and prognostic assessment of patients with acute decompensated heart failure and correlate with left ventricular dilatation, remodeling, and dysfunction. The median plasma NT-pro-BNP is increased in diabetic patients without overt cardiovascular disease, suggesting a higher prevalence of asymptomatic left ventricular dysfunction. In a large population of patients hospitalized for acute MI diabetes was a strong and independent factor for increased plasma NT-pro-BNP levels. The latter were associated with the increased incidence of in-hospital mortality and cardiogenic shock observed in diabetic patients after myocardial infarction, indicating that plasma NT-proBNP provides relevant prognostic information on in-hospital outcome in this population [16]. In a crosssectional sample of type 1 diabetic patients an association between NT-proBNP and vascular 
complications depended on circulating levels of the inflammatory cytokine tumor necrosis factor: TNF- $\alpha$ [17]. TNF- $\alpha$ has pleiotropic effects in cytokine-mediated inflammation underlying vascular disease and the link between type 1 diabetes, TNF- $\alpha$ and vascular disease is well established [18]. However, the relationship between TNF- $\alpha$ and oxidative stress is not clear in a dose- and time-dependent manner, a dual role of TNF- $\alpha$ being observed. After TNF$\alpha$ perfusion in isolated heart, an increase of catalase activity were observed while the superoxide dismutase activity remained unchanged. Other studies conducted in the heart have reported an oxidative stress with an activation of catalase and no change in superoxide dismutase. An explanation for this observation may be a difference in the dynamic and the spatial distribution between these two enzymes. [19-21].

\section{Free radicals and antioxidants (Figure 1)}

Radicals derived from oxygen (ROS) and nitrogen (RNS: derived from nitric oxide: NO) are the largest class of radical species generated in living systems. ROS and RNS are products of normal cell metabolism and have either beneficial or deleterious effects, depending on the concentration reached in the tissues $[22,23]$. Free radicals can be defined as molecules or molecular fragments containing one or more unpaired electrons in molecular orbits. These unpaired electrons give a considerable degree of reactivity to the free radical. ROS are produced as intermediates in reduction-oxidation (redox) reactions leading from $\mathrm{O}_{2}$ to $\mathrm{H}_{2} \mathrm{O}$. The endothelium is located in a strategic anatomical position within the blood vessel wall and thus constitutes a barrier between the blood and all tissues. This metabolically active monolayer organ is exposed to different biomechanical and biochemical stimuli to which it responds by preserving the integrity and homeostasis of vascular function. Accumulating 
evidence indicates the important role of redox signaling in the triggering and mediation of these actions. Of the ROS generated in endothelial cells, the major sources of superoxide anions include nicotinamide dinucleotide phosphate (NADPH) oxidases, xanthine oxidases, cyclooxygenases (COXs), mitochondria, and, under certain conditions, endothelial NO synthases (NOS) [24]. Upon stimulation by angiotensin II, the activity of NADPH oxidases is increased in endothelial and smooth muscle cells, suggesting that in the presence of an activated renin-angiotensin system (either local or circulating), dysfunction due to increased vascular production of superoxide anions is to be expected $[25,26]$. Another source of ROS is xanthine oxidase. This enzyme catalyzes the sequential hydroxylation of hypoxanthine to yield xanthine and uric acid. The enzyme exists in two forms that differ primarily in their oxidizing substrate. The dehydrogenase form preferentially uses $\mathrm{NAD}^{+}$as an electron acceptor, but is also able to donate electrons to molecular oxygen.

The mitochondria are the major source of ROS production within the cell, and their increased levels are probably the culprit in a variety of pathophysiological conditions, including type 2 diabetes. Recently, another pathway for mitochondrial ROS regulation has been discovered involving the p66Shc (p66) protein. p66 is a protein encoded by the ShcA gene that is expressed as three isoforms of about 46,52 , and $66 \mathrm{kDa}$ in mammals. Some studies have shown that p66Shc is very important for the regulation of the intracellular redox balance and oxidative stress. Levels p66Shc appeared to decrease the expression of ROS scavenging enzymes through the inhibition of FOXO transcription factors, causing a decrease in the expression of ROS scavenging enzymes [27, 28]. p66Shc is a protein acting specifically in the mitochondrion as a redox enzyme that generates $\mathrm{H}_{2} \mathrm{O}_{2}$; the $\mathrm{H}_{2} \mathrm{O}_{2}$ generated by p66Shc accounts for $\sim 30 \%$ of the total pool of intracellular $\mathrm{H}_{2} \mathrm{O}_{2}$ and is biologically relevant. Under normal cellular conditions, p66ShcA is sequestered by peroxiredoxin 1 ( Prx1) in an inactive form. Under the cellular stressors associated, p66ShcA is disassociated from Prx1and is serine 
phosphorylated by PKC- $\beta$. Phosphorylated p66ShcA forms a complex with Pin1 isomerase, which leads to p66ShcA translocation into the intermitochondrial space (IMS). There, p66ShcA oxidizes cytochrome $\mathrm{c}$ and reduces oxygen to form mitochondrial ROS [29, 30]. The p66(Shc) gene has emerged as a novel gerontogene affecting health throughout life, westernized lifestyle (hypercaloric diet) and during aging. High glucose determines the overproduction of ROS by the mitochondria and it has been reported that p66ShcA was a gene that regulated the apoptotic responses to oxidative stress [31]. The role of p66shc in the context of IR has been investigated. Interestingly, it appears that p66 participates in insulin desensitization of fat cells by excess nutrients [32].

In return, paradoxally, definitive data to demonstrate that superoxide anion production is stimulated in diabetic organs in vivo, however, is lacking. Recently, new results demonstrate that diabetic kidneys have reduced superoxide and mitochondrial biogenesis. It is hypothesized that an overall reduction in mitochondrial superoxide production could be due to a redistribution of carbons and electrons away from mitochondria and to the cytosol [33]. The relevance of p66Shc in the clinical setting of diabetes is supported by the notion that p66Shc gene expression is increased in mononuclear cells obtained from patients with type 2 diabetes and correlates with plasma 8-isoprostane levels, an in vivo marker of oxidative stress [34]. Finally according the recent studies, p66Shc appears as a crucial mediator of sustained vascular hyperglycemic stress in diabetes and provides molecular insights for understanding the progression of diabetic vascular complications despite optimal glycemic control [35].

On the other hand, it is likely that mitochondrial superoxide production plays an important signaling role and is necessary for normal physiologic intracellular communication. In pathological conditions or treatments (e;g; anthracyclins), increased oxidative stress within mitochondria arising from impaired oxidative metabolism may contribute to greater lipid peroxidation and damage to cell membranes and DNA, thus activating a cascade of signaling 
events that further exacerbate the severity of the disease. Altering mitochondrial fusion and fission events influences ROS production in mitochondria. In addition to their involvement in the electron transport system, mitochondria also generate $\mathrm{H}_{2} \mathrm{O}_{2}$ from monoamine oxidase (MAO) bound to their outer membrane. MAO is an enzyme responsible for the metabolism of endogenous amines, and is a substantial source of $\mathrm{H}_{2} \mathrm{O}_{2}$ and oxidative stress in CVD such as diabetes [36]. Mitochondria have long been known to generate significant quantities of hydrogen peroxide. Hydrogen peroxide does not contain an unpaired electron and thus is not a radical species stricto sensu. Under physiological conditions, the production of hydrogen peroxide is estimated to account for about $\sim 2 \%$ of the total oxygen uptake by the organism.

The major RNS is endothelium-derived nitric oxide or ${ }^{\circ} \mathrm{NO}$. It is a potent gaseous mediator widely accepted as a key determinant of endothelial function produced by endothelial nitric oxide synthase (eNOS). NO has potent vasodilator, anti-inflammatory and anti-thrombotic properties $[37,38]$. Under physiological conditions, in the presence of substrate (L-arginine) and co-factors (tetrahydrobiopterin: $\mathrm{BH}_{4}$ ) eNOS produces ${ }^{\circ} \mathrm{NO}$ [24]. Under conditions of low $\mathrm{BH}_{4}$ bioavailability relative to NOS, oxygen activation is "uncoupled" from L-arginine oxidation, and NOS produces superoxide instead of NO. On the other hand, the synthesis of NO may be blocked by inhibition of the active site of the enzyme by guanidino-substituted analogues of L-arginine such as asymmetric dimethylarginine (ADMA) a naturally occurring amino acid found in the plasma and various tissues. Plasma levels of ADMA in humans and rats in most studies range from 0.3 to $0.5 \mathrm{mmol} / \mathrm{L}$ [39]. ADMA and arginine methylation of organ proteins are modified during diabetogenesis. Thus, plasma levels of ADMA are elevated in patients with type 1 or type 2-diabetes [40]. Increased production of ADMA is probably associated with the development of obesity and diabetes, and arginine methylation plays a role in cardiovascular and metabolic pathologies [41]. The elevated levels of ADMA could in part be secondary to the early development of oxidative stress [42]. An elevated 
serum ADMA levels is one of the earliest signs of vascular dysfunction and IR in type-2 diabetes [43].

The free radical ${ }^{\circ} \mathrm{NO}$ has a half-life of only a few seconds in an aqueous environment. $\mathrm{NO}$ reacts with molecular oxygen and ROS to generate a range of oxidation products including RNS One well-characterized RNS-forming reaction is that of ${ }^{\circ} \mathrm{NO}$ with superoxide $\left(\mathrm{O}_{2}{ }^{-}\right)$, which occurs at nearly diffusion-limited rates to produce peroxynitrite: $\mathrm{ONOO}^{-}$. The latter itself is strongly oxidizing, and when protonated, undergoes homolytic scission to produce hydroxyl radical $\left({ }^{\circ} \mathrm{OH}\right)$ and nitrogen dioxide $\left(\mathrm{NO}_{2}\right)$. Additional reactive radicals derived from other endogenous molecules [e.g. carbon monoxide (CO), nitrogen dioxide and hydroperoxyl can be formed in living systems [44-46].

Exposure to free radicals from a variety of sources has led organisms to develop defense mechanisms in the form of antioxidant agents. An antioxidant can be defined as any substance that, when present in very low concentrations compared to that of an oxidizable substrate, significantly delays or inhibits the oxidation of that substrate. Defense mechanisms against free radical-induced oxidative stress involve: (a) preventive mechanisms, (b) repair mechanisms and (c) antioxidant defenses. Enzymatic antioxidant defenses include superoxide dismutases (SOD), glutathione peroxidases (GPx), catalases (CAT) and other enzymes such as Prx er, metallothioneins (MTs) or thioredoxin. Non-enzymatic antioxidants are represented by vitamins [ascorbic acid (Vitamin C), tocopherol (Vitamin E)] and other direct glutathione (GSH, folic acid, lipoic acid, thiols and indirect (chelating redox metals, pharmacological drugs) antioxidants. In the body, an excess or deficiency of metal ions can potentially inhibit protein function, interfere with correct protein folding or, in the case of iron or copper, promote oxidative stress [47]. The involvement of metal ions in disorders such as diabetes has 
made them an emerging target for therapeutic interventions. Iron is able to catalyze the formation of potentially toxic free radicals. Excessive iron is sequestered by ferritin in a nontoxic and readily available form in the cell. When ceruloplasmin, which requires $\mathrm{Cu}$ for its ferroxidase function, is low, the mobilization of Fe to transferrin can be impaired, and $\mathrm{Fe}$ accumulates in tissues as has been observed in $\mathrm{Cu}$-deficient animals, as well as in humans lacking functional ceruloplasmin [48]. Concerning the regulation of zinc levels, MTs play a key role in its distribution in the intracellular space. MTs belong to the group of intracellular cysteine-rich, metal-binding proteins [49]. The role of zinc has been extensively studied in recent years; it influences redox state, enzyme activity, gene transcription, and energetic metabolism. MTs may play a key role in protecting the organs against high glucose-induced ROS and subsequent inflammation in diabetic pathology [50].

Under normal conditions, there is a balance between the generation of ROS and the activity/ intracellular levels of the antioxidant defense mechanisms. Oxidative stress is often defined as an imbalance between pro-oxidants and antioxidants. The aging process itself is regulated by such an oxidative stress imbalance [25, 51], combined with a disruption of thiol-redox circuits, which leads to aberrant cell signaling and dysfunctional redox control [52]. In the blood, oxidative stress results from an imbalance between pro-oxidants and antioxidants, which can be quantified as the redox state of plasma glutathione/glutathione disulphide: GSH/GSSG. As details become available concerning subcellular redox organization, a new generation of targeted antioxidants may become available which restore redox signaling and facilitate disease prevention $[53,54]$.

Lipids are particularly vulnerable to oxidation because membranes of some cells are rich in polyunsaturated fatty acids and because of the presence of oxygen at millimolar levels in the lipid bilayer. Unsaturated phospholipids, glycolipids, and cholesterol in cell membranes and 
other organized systems are prominent targets of oxidant attack. This can result in lipid peroxidation, a degenerative process that disturbs structure/ function of the target system. Lipid hydroperoxides (LOOHs) derived from unsaturated phospholipids, glycolipids, and cholesterol are prominent intermediates of peroxidative reactions induced by activated species such as hydroxyl radical, peroxyl radicals, singlet oxygen, and peroxynitrite .The inner mitochondrial membrane contains cardiolipin; which is an unsaturated phospholipid specifically localized in this compartment. Cardiolipin levels diminish under when lipid peroxidation is prominent as observed in aging and diabetes [55].

Increased oxidative stress associated with lipid peroxidation in endothelial cells may be one of the major causes of hyperglycemia-triggered diabetic complications. Endothelial dysfunction is characterized by increased pro-oxidant activity and the unbalanced production/release of mediators. In the pathogenesis of diabetes, metabolic factors, oxidative stress and inflammation converge and stimulate monocyte adhesion to endothelial cells [2]. Aging is associated with an increase in oxidative stress [25]. In the plasma, oxidative stress index is increased in type 1 and type 2 diabetic patients [56]. Diabetic patients exhibit reduced NOdependent vasodilatations [57].

In summary, under conditions of oxidative stress, free radicals that are not reduced or removed from the cellular environment can cause damage to all cellular macromolecules including nucleic acids, lipids and proteins. Oxidation of lipids can cause changes in the structure and fluidity of membranes that are detrimental to cellular processes and functions.

\section{Metabolic stress and diabetes (Figure 2)}

\subsection{Oxidative and nitroxidative stress}

Given the multiplicity of their functions, mitochondria are a logical target for the study of metabolic diseases. Skeletal muscle is the major site of insulin-stimulated glucose use in the 
body, and the dysregulation of mitochondria is closely associated with IR in skeletal muscle and thus with the pathogenesis of type 2 diabetes. Inside mitochondria, electrons from reduced substrates move from complexes I and II of the electron transport chain through complexes III and IV to oxygen, forming water and causing protons to be pumped across the mitochondrial inner membrane. The electron transport system is organized so that the level of ATP can be precisely regulated [58]. Hyperglycemia-induced overproduction of superoxide anions by the mitochondrial electron transport chain triggers a maladaptive response by affecting several metabolic and signaling pathways involved in diabetic complications.

Diabetes mellitus is characterized by a number of metabolic abnormalities, in particular IR and hyperglycemia, but also hyperlipidemia, elevated free fatty acids (FFA), increased quantities of advanced glycation end-products (AGEs), and exaggerated superoxide anion production [59]. All these metabolic abnormalities can activate pathways that alter the function and structure of blood vessels and tissues. The increased superoxide anion production is associated with the activation of major pathways involved in the pathogenesis of diabetic complications: 1) polyol pathway flux, 2) increased formation of AGEs, 3) activation of protein kinase $\mathrm{C}$ isoforms, and 4) over-activity of the hexosamine pathway. The accelerated flux of sorbitol through the polyol pathway has been implicated in the pathogenesis of secondary diabetic complications: cataractogenesis, retinopathy, neuropathy, nephropathy and CVD. In addition, free carnitine and myo-inositol content in the caudal nerves were decreased with polyol accumulation in diabetic rats. These actions are accompanied by inactivation of enzymes such as eNOS [57].

Concerning the polyol pathway, aldose reductase (AKR1B1, in humans), which belongs to the aldoketo-reductase super family of proteins, catalyzes the first and rate-limiting step of this pathway for glucose metabolism. An increased flux through the polyol pathway could alter the NADPH/NADP ratio and attenuate the glutathione reductase (GR) and glutathione 
peroxidase (GPx) system thereby decreasing the reduced glutathione/oxidized glutathione (GSH/GSSG) ratio, which would cause oxidative stress. The different pathogenic mechanisms described above are interrelated in hyperglycemia-induced processes.

Insulin exerts important redox-regulating actions in various target organs, implying an antioxidative role of the hormone [60]. The generation of ROS by mitochondrial oxidative phosphorylation is attenuated by insulin through the regulation of uncoupling protein (UCP) expression. In addition, the expression of NADPH oxidases (NOX) is inhibited by insulin [61]. Several Nox isoforms are present in the vasculature, Nox1, Nox2, Nox4, and Nox5. These isoforms have been proposed to play an important role in vascular pathobiology. In cultured adipocytes, excess glucose and palmitate generate ROS via NOX4 rather than by mitochondrial oxidation. NOX4 is regulated by both NADPH generated in the pentose phosphate pathway and translocation of NOX4 into lipid rafts, leading to the expression of monocyte chemotactic factors [62]. In vascular cells, Nox1 mRNA expression is low under physiological conditions but induced in the presence of factors elevated in diabetes mellitus, and other pathological conditions such as atherosclerosis and hypertension. A recent study demonstrated a major role for Nox1 derived ROS in diabetes mellitus-associated atherosclerosis [63].

\subsection{Intracellular signaling (Figure 3)}

Oxidative stress is the common denominator for the major pathways involved in the development and progression of diabetic diseases. Mechanisms implicated in the increased generation of ROS include: $\mathrm{NAD}(\mathrm{P}) \mathrm{H}$ oxidases, advanced glycation end-products (AGE), defects in the polyol pathway, uncoupled NOS and the mitochondrial respiratory chain via oxidative phosphorylation. Excess amounts of ROS and RNS modulate activation of protein 
kinase $\mathrm{C}$, mitogen-activated protein kinases, and various cytokines and transcription factors such as FOXO, Nrf2, AP -1, NF- $\kappa$ B, PPARS and Bach 1.

\subsubsection{FOXO}

Forkhead box O (FOXO) transcription factors include FOXO1, FOXO3, and FOXO4. They are critical mediators of oxidative stress and are activated by various cellular stress stimuli. FOXO proteins modulate normal cellular function but also contribute to pathological processes. Metabolic signaling via these transcription factors is conserved in many species FOXO transcription factors can also be viewed as sensors for oxidative stress since their activity is regulated by $\mathrm{H}_{2} \mathrm{O}_{2}$, depending on the cellular context, they relay these stresses to induce apoptosis [64]. An increase in intracellular ROS facilitates the localization of FOXO to the nucleus, where it is transcriptionally active. Oxidative stress regulates FOXO activity through various posttranslational modifications including phosphorylation, acetylation, and ubiquitination. FOXO proteins play an important role in protecting cells against oxidative stress. Indeed, cells activate FOXO transcription factors to reduce the level of oxidative stress by inducing enzymes that breakdown ROS such as MnSOD and catalase. Hyperglycemiainduced oxidative stress promotes inflammation. Inflammation is a major risk factor in diabetes and is associated with the progression of diabetic complications.

An important function of FOXO proteins is their ability to govern cardiovascular cell development, new vessel growth and smooth muscle cell proliferation [65]. Members of the FOXO family of transcription factors suppress tumor angiogenesis by inhibiting endothelial cell migration. In light of these actions, these transcription factors may have a significant role in the vascular disorders that accompany diabetes. New capillary formation from pre-existing vessels is uncontrolled in diabetes. FOXO proteins can stimulate the insulin-like growth factor binding protein-1 (IGFBP1) promoter by binding to its insulin- responsive sequence. 
FOXO proteins participate in carbohydrate and fatty acid metabolism [66]. In particular, FOXO1 plays a significant role in regulating whole body energy metabolism. In diabetes, FOXO1-dependent gene expression promotes some of the deleterious characteristics associated with this pathology. [67, 68].

\subsubsection{NRF2}

Oxidative stress is often seen as an imbalance resulting from altered gene expression. The transcription factor called nuclear factor (erythroid-derived 2)-like 2, or Nrf2 is referred to as the "master regulator" of the antioxidant response; it modulates the expression of hundreds of genes, including not only those that control antioxidant enzymes, but also genes that control immune and inflammatory responses [69]. Insulin may promote the elimination of ROS through the up-regulation of various antioxidant enzymes, and the production of intracellular antioxidants in an Nrf2-Keap1-dependent pathway. Control of nuclear trafficking is crucial under disease conditions such as diabetes, and it occurs at several levels. Nrf2 is a key player in the antioxidant response. Under non-stress conditions, concentrations of the transcription factor Nrf2 are low, and the protein is retained in the cytoplasm owing to its association with Keap1. In response to oxidative stress, a complex series of events leads to the stabilization of Nrf2 and its translocation into the nucleus [70]. In the nucleus, Nrf2 upregulates the expression of several genes that are implicated in the antioxidant response, and for which the promoter region contains an antioxidant response element (ARE)[71]. The Keap1-Nrf2-ARE pathway can be activated by various cellular stresses (including oxidative stress, endoplasmic reticulum stress, and shear stress) and chemical inducers from both endogenous (reactive oxygen and nitrogen species) and exogenous sources. The system responds to oxidative stress by expressing a broad range of cytoprotective enzymes. The classes of these Nrf2-regulated genes include those that express electrophile conjugating enzymes and antioxidative enzymes 
[72]. The pharmacological manipulation of Nrf2 may be beneficial in treating metabolic disorders such as diabetes, and in particular Nrf-2 activators potentially may protect peripheral nerves from hyperglycemic stress. Vitamin E, one of the most widely-tested antioxidants for the treatment of diabetic neuropathy influences antioxidant and detoxifying enzymes regulated by Nrf2 [73].

\subsection{3. $A P-1$}

The AP-1 family of transcription factors consists of Jun family oncoproteins that homo- or heterodimerize with other members of the Jun or Fos protein families. Inducible gene expression via AP-1 is involved in a diverse range of cellular responses including antioxidant

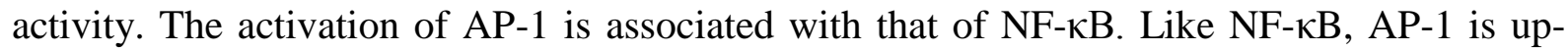
regulated by a wide variety of pro-oxidant and pro-inflammatory stimuli. Functional AP-1 sites, which mediate inducer-dependent gene expression of HO-1, have been identified in the promoter regions of human HO-1 genes [74]. A potential link exists between inflammation and these complex regulatory circuits. The elevated levels of ROS during hyperglycemia, peroxidative stress and cytokine production trigger the inflammatory response in tissues by up-regulating several redox-sensitive transcription factors such as AP-1 [75].

\subsection{4. $N F-\kappa B$}

The nuclear factor-kB $(\mathrm{NF}-\kappa \mathrm{B})$ family of transcription factors plays a crucial role in inflammation, immunity, cell proliferation, development, survival and apoptosis. In humans,

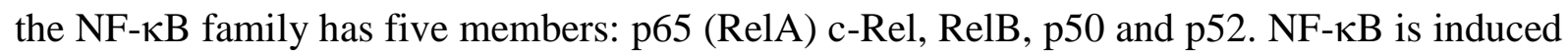
by a variety of extra-cellular stimuli via the activation of membrane and cytosolic receptors. In most non-stimulated cells, NF- $\mathrm{BB}$ is maintained inactive in the cytoplasm by endogenous inhibitors: I- $\kappa$ B. Some inflammatory cytokines activate this pathway [76]. In response to a 


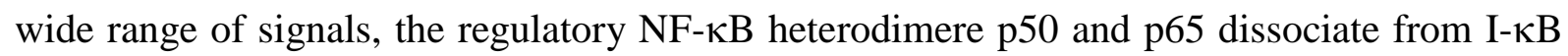
and subsequently translocate to the nucleus. Oxidative stress and/or depletion of reduced glutathione (GSH) induce subsequent increases in the cytosolic oxidized form of glutathione: GSSG in response to oxidative stress causes rapid ubiquitination and phosphorylation and thus subsequent degradation of $\mathrm{I}-\kappa \mathrm{B}$ which is a critical step for NF- $\kappa \mathrm{B}$ activation. Hyperglycemia and the subsequent generation of advanced glycation end-products (AGEs) and fatty acid degradation are major promoting sources of ROS within cells and NF- $\kappa \mathrm{B}$ is activated by these stimuli. [77] [78].

\subsubsection{PPARS}

Peroxisome proliferator-activated receptors (PPARs) are ligand-dependent transcription factors. Three different PPAR isoforms have been identified in humans. PPARs are therefore important targets in the treatment of metabolic disorders. They are key regulators of fatty acid and lipoprotein metabolism, glucose homeostasis, cellular proliferation/differentiation and the immune response. The isoforms possess distinct functions, and vary in their ligand affinity, expression, and activity in different metabolic pathways. PPAR $\gamma$ plays a crucial role in glucose homeostasis and is involved in the regulation of lipid metabolism and adipocyte differentiation and function. PPAR $\gamma$ is largely expressed in adipose tissue, in skeletal muscle, locally in the vasculature, including endothelial cells, smooth muscle cells and macrophages, where PPAR isoforms exert much of their metabolic action [79]. PPAR agonists modify circulating lipid levels, and thereby reduce cardiovascular risk in patients with diabetes. Treatment of diabetic apoE KO mice with either a PPAR $\alpha$ or a PPAR $\gamma$ agonists is associated with a reduction in vascular superoxide anion production, together with reduced gene expression of the NAD(P)H oxidase subunits p47phox and gp91phox in the aorta of [80]. In $\mathrm{db} / \mathrm{db}$ and diet-induced obese mice, PPAR $\gamma$ activation by rosiglitazone restores endothelium- 
dependent relaxations of the aorta, whereas diabetic mice lacking adiponectin or treated with an anti-adiponectin antibody do not respond [81]. Adiponectin activates AMPK/eNOS and cAMP/PKA signaling pathways, which increases NO bioavailability and reduces oxidative stress. These results demonstrate that adipocyte-derived adiponectin is required for the PPAR $\gamma$-mediated improvement of endothelial function in diabetes. Adiponectin, an adipocytespecific hormone, circulates at relatively high levels in healthy humans, but at reduced levels in obese subjects [82]. It increases cellular anti-oxidative defense mechanisms and inhibits oxidative stress in a significant and dose-dependent manner in Human 22Rv1 and DU-145 PC cell lines [83]. In addition, PPARs suppress inflammation by inhibiting the activity of AP1 and NF- $\mathrm{B}$ [84].Finally, PPARs may play a major role in the protection against macrovascular disease and the amelioration of microvascular defects in type 2 diabetes.

\subsubsection{Bach1}

The transcription factor Bach1 (BTB and CNC homology 1, basic leucine zipper transcription factor 1) inhibits oxidative stress-inducible genes and is a crucial negative regulator of oxidative stress-induced cellular senescence [85]. Bach1 forms a heterodimer with small Maf oncoproteins and binds to the Maf-recognition element (MARE) to inhibit target genes [86]. Epoxygenase activity and synthesis of epoxyeicosatrienoic acids (EETs) are important modulators of obesity and diabetes. Mesenchymal stem cells expressed substantial levels of EETs, and inhibition of soluble epoxide hydrolase increased the level of EETs and decreased adipogenesis. Treatment with EET agonists increased HO-1 expression by inhibiting Bach-1, a negative regulator of $\mathrm{HO}-1$ expression [87]. 


\subsubsection{Other transcription factors implicated in oxidative stress regulation and diabetes}

Other transcription factors bind to specific regulatory elements in the promoters of dependent genes and control gene expression by interacting with histone-modifying enzymes or the transcriptional machinery. These factors initiate the expression of target genes in the vessel wall and in the myocardium. Activation transcription factor 4 (ATF4) is a master regulator for evolutionarily conserved mammalian stress response pathways, in particular in the cardiovascular pathological setting. It controls factors implicated in atherogenesis, restenosis and diabetes by controlling the expression of growth factors, cytokines, chemoattractants and adhesion molecules [88].

Hypoxia-inducible factor (HIF) is another transcription factor of importance. Activation of the HIF system represents a major adaptation in ischemic and metabolic disorders [89]; however, it also occurs in disorders where the primary stimulus is typically not hypoxic in nature. The HIF system can take on both adaptive and maladaptive roles in the cardiovascular system depending on the context [90]. HIF-1 $\alpha$ stability and function are compromised by high glucose concentrations. Diabetes is associated with hypoxia and impairs ischemia-induced neovascularisation associated with other forms of adaptive cell and tissue responses to low oxygen levels. Hyperglycemia appears to be the driving force of such deregulation. Destabilization of hypoxia-inducible HIF-1 is most likely the event that transduces hyperglycemia into the loss of the cellular response to hypoxia in most diabetic complications [91].

As a member of the interferon regulatory factor IRF family of transcription factors, interferon regulatory factor 4 (IRF4) is expressed in most cell types of the immune system. It is essential for the development and function of $\mathrm{T}$ helper (Th), regulatory $\mathrm{T}$ (Treg), B, as well as dendritic (DC) cells. Since these cells are crucial in the autoimmune responses, IRF4 may contribute to the initiation and progression of autoimmune diseases, such as type I diabetes [92]. A 
relationship exists between immune response and oxidative stress in cardiovascular disease. Thus, a novel N-terminal truncated intracellular isoform of metalloproteinases: MMP-2 is induced by oxidative stress and this isoform initiates a primary innate immune response that may contribute to progressive cardiac dysfunction in the setting of ischemia and heart failure [93].

\subsection{Electrophile stress (Figure: 3 )}

Another important mechanism in this field is the implication of electrophile metabolism in the initiation and development of diabetes. Oxidative stress is the primary event, whereas lipid peroxidation products are second messengers that convey to the cell information about the initiating oxidative event. In membranes, polyunsaturated fatty acids (PUFA) are highly susceptible to oxidation and readily undergo peroxidation by enzymatic or free radical chain reaction mechanisms, yielding numerous electrophilic species [94]. If lipid peroxides are not neutralized by endogenous antioxidants, they will fragment unsaturated and diffusible aldehydes (acrolein; 4-hydroxynonenal (HNE); and 4-hydroxyhexenal (HHE), 4-ONE: 4oxononenal; MDA: malondialdehyde). These are highly reactive electrophiles [95], and like ROS/RNS, they are capable of covalently modifying proteins, DNA and other macromolecules. In these conditions, arachidonic acid and longer-chain fatty acids are modified and produce these electrophilic species [96]. Several nucleophilic amino acids are present in biological systems; sulfhydryl groups on cysteine residues are the softest. ROS oxidation of these cysteines produces protein conformational changes that stimulate antioxidant pathways through subsequent induction of gene expression after activation of the Nfr2-Keap1 pathway. Cellular exposure to these byproducts of lipid peroxidation, such as 4HNE, may accelerate the onset and development of chronic diseases such as diabetes [97]. In 
3T3-L1 adipocytes, 4-HNE treatment at non-toxic concentrations increased levels of 4-HNEinsulin receptor substrate (IRS) adducts, leading to adipocyte IR [98].

Short-term exposure to $4-\mathrm{HNE}$ at concentrations as low as $10 \mu \mathrm{M}$, a concentration reportedly reached in certain pathological conditions, induces $\mathrm{Ca}^{2+}$ influx and subsequent insulin secretion. These results suggest that the electrophile positively regulates functional insulin secretion, which is consistent with previous findings indicating that the ROS produced in mitochondria are able to induce insulin secretion. Increased intracellular GSH by pretreatment with L-cysteine prevents $4-\mathrm{HNE}-$ induced increases in $\left[\mathrm{Ca}^{2+}\right]_{\mathrm{i}}$ and insulin secretion following short-term exposure [99].

The genomic regulation common to most electrophiles is the Nrf2/Keap1 (Nuclear erythroid 2-related factor 2/Kelch $\mathrm{ECH}$ associating protein) pathway. An important target of electrophiles, associated with PPAR $\gamma$, is a nuclear receptor involved in the regulation of lipid metabolism and cell differentiation, and the target of the thiazoladinedione (TZD) class of antihyperglycemic drugs. In addition, electrophiles down-regulate pro-inflammatory gene expression induced by $\mathrm{NF}-\kappa \mathrm{B}$.

Based on these particular chemical properties, HNE has been considered a second messenger of oxidative damage. Direct conjugation of the C2-C3 double bond of enals with the sulfhydryl group of GSH is a major route for the metabolism and detoxification of enals with the formation of compounds such as glutathione-4-hydroxy-trans-2-nonenal (GS-NHE) and glutathionyl-1,4-dihydroxynonene (GS-DHN). 4HNE controls the expression and activity of many signaling proteins involved in IR [100]. In cardiac muscle, this effect is partially mediated by activation of PPAR-alpha, probably through interactions with long-chain fatty acid ligands. Enhanced fatty acid oxidation leads to redox imbalances via an increased $\mathrm{NADH} / \mathrm{NAD}^{+}$ratio, which further inhibits glucose oxidation and promotes ROS production. 
The physiological formation of a unique nitrated cyclic nucleotide, 8-nitroguanosine 3',5'cyclic monophosphate (8-nitro-cGMP) and its potent antioxidant activity. It is a new second messenger derived from cGMP in mammals. 8-Nitro-cGMP regulates the redox-sensor signaling protein Keap1. It is a new area of oxidative stress research [101].

In summary, oxidative stress not only promotes the development of diabetes, but diabetes also triggers the increase in oxidative stress due to elevated blood glucose and free fatty acids. Such disease-induced ROS production further exacerbates cellular damage and contributes to diabetic complications. The increased expression of antioxidative enzymes and the modulation of pro-inflammatory cytokine signaling in an Nrf2- dependent manner have been demonstrated. Nrf2 is a redox-sensitive transcription factor that activates cytoprotective pathways against oxidative injury, inflammation, and apoptosis through transcriptional induction of a broad spectrum of genes involved in electrophilic/drug detoxification and antioxidant protection [71]. Evidence from a variety of model systems points out an important role of Nrf2 in prevention of diabetes and diabetes complications. The pharmacological activation of the Nrf2 pathway opens the possibility that other dietary Nrf2 activators such as sulforaphane may also have effects on cellular lipid and glucid metabolisms and total energy expenditure \{Vomhof-Dekrey, 2012 \#2392\}. Sulforaphane is an isothiocyanate that is found in cruciferous vegetables and has a strong cytoprotective function against oxidative stress and plays a critical role in preventing diabetes-induced damage $\{$ Bai, $2013 \# 2393$ \}.

\subsection{Sphingolipid signaling}

Cellular signaling mechanisms regulated by sphingolipids are being recognized as critical players in metabolic diseases [102]. The control of sphingolipid synthesis by cells is regulated by substrate availability as well as by other mechanisms related to lipid composition and 
membrane homeostasis. An extensive network of enzymes metabolizes sphingolipids into bioactive lipid mediators. Sphingomyelinase forms ceramide via a hydrolytic reaction. Ceramide is further converted to sphingosine by ceramidases. Sphingosine, once phosphorylated into sphingosine 1-phosphate (S1P) formed in endothelial and hematopoietic cells, is secreted into the extracellular space by transporters. Due to its amphipathic character, most of the S1P is bound to carrier proteins in the blood .In human plasma, more than half of the $\mathrm{S} 1 \mathrm{P}$ is found in the HDL fraction, about $36 \%$ in the albumin fraction, and $8 \%$ in the LDL fraction. The ability of HDL to induce vasodilation, endothelial protection [103] and cardioprotection was dependent on S1P [104]. Diverse physiological functions of S1P are mediated by specific, high-affinity G-protein-coupled receptors, GPCRs. Five receptors for S1P (S1PR1-5), have been identified. Extracellular S1P signals via its five GPCR to regulate numerous organ systems. The signaling properties of the S1P receptors are well characterized, and some physiological roles of S1P have been elucidated by the analysis of mutant mice for receptors and by the use of pharmacological tools. S1P, abundantly expressed in the vascular compartment, is an important player in the regulation of the extent and duration of inflammatory reactions $[105,106]$. Sphingolipid metabolism is altered in diabetic conditions. However, to date, studies in this area have focused on ceramide, and only a few studies have examined the involvement of S1P. Fatty acid (palmitate)-induced stimulation of de novo ceramide synthesis is required. Moreover, the inhibition of sphingolipid synthesis has been shown to increase insulin sensitivity [107]. Plasma S1P levels are elevated in two animal models of type 1 diabetes (streptozotocin-induced diabetic rats and Ins2 Akita diabetic mice), yet no changes in levels were detected in the livers of these animals, suggesting there are other sources of S1P [108]. An interesting link has been demonstrated between adiponectin and ceramide, and insulin sensitivity. Binding of adiponectin to its two receptors, AdipoR1 and AdipoR2, stimulates ceramidase activity, by a mechanism resulting in the formation of 
S1P via a sphingosine kinase-dependent pathway [109]. This effect may be important for reducing IR and liver pathologies associated with metabolic dysregulation such as diabetes. 


\section{Insulin resistance (IR) and oxidative stress}

In skeletal muscle and adipose tissue, an increase in insulin promotes glucose uptake by activating a complex cascade of signaling events. Binding of insulin to the insulin receptor leads to downstream tyrosine phosphorylation of protein substrates that then activate PI3K. This is associated with GLUT4 translocation from its intracellular pool to the plasma membrane, and glucose transport into the cell. IR is defined as an inadequate response by insulin target tissues, such as skeletal muscle, the liver, and adipose tissue, to the physiologic effects of circulating insulin. The important consequences are decreased insulin-stimulated glucose uptake in skeletal muscle, impaired insulin-mediated inhibition of hepatic glucose production in the liver, and a reduced ability of insulin to inhibit lipolysis in adipose tissue. We discuss here how nutrient availability and obesity interact to modulate inflammatory pathways in relationship with oxidative stress in 1) the pancreas 2) adipose and skeletal tissue 3) the liver.

\subsection{Pancreas, insulin resistance and oxidative stress:}

Various inflammatory cytokines and oxidative stress produced by pancreatic islet-infiltrating immune cells play an important role in mediating the destruction of beta cells. Beta-cell dysfunction and IR are the hallmarks of type 2 diabetes. Under diabetic conditions, chronic hyperglycemia induces an alteration in pancreas function and aggravates IR; these actions are associated with oxidative stress. Beta cells are vulnerable to oxidative stress because of their relatively low expression of antioxidant enzymes such as catalase and glutathione peroxidase. In the diabetic state, hyperglycemia and the subsequent production of oxidative stress decrease insulin gene expression and secretion. Indeed, the expression of oxidative stress markers such as 8-hydroxy-2-deoxyguanosine (8-OHdG) and 4-hydroxy-2,3-nonenal (4HNE) were increased in islets under diabetic conditions. the decrease in insulin gene 
expression after prolonged exposure to a high glucose concentration was prevented by treatment with antioxidants such as probucol [110], glutathione peroxidase [111], or N-acetylL-cysteine (NAC), vitamins C or E, or both [112]. Activation of the JNK pathway is associated with a reduction in insulin gene expression induced by oxidative stress; suppression of the JNK pathway protects cells from oxidative stress. It is likely that activation of the JNK pathway leads to decreased PDX-1 and Mafa activity; these cellular actions are associated with suppression of insulin gene transcription found in the diabetic state. In this context, PDX-1 and Mafa are two important pancreatic transcription factors [113, 114]. Mafa overexpression in the liver, together with PDX-1 dramatically ameliorated glucose tolerance [115].

Beta-cell dysfunction is the result of either chronic exposure to hyperglycemia or FFA, or a combination of both. In cells exposed to sustained high glucose concentrations, more glucose is being oxidized in the TCA cycle, which leads to an increase in ROS generation. In IR syndrome, there is an increased FFA flux from adipocytes into arterial endothelial cells that might result in increased FFA oxidation by the mitochondria. In vitro elevated levels of FFA induce numerous adverse effects on mitochondrial function including the uncoupling of oxidative phosphorylation and the generation of ROS [116]. In vitro, long-term exposure to FFA inhibits insulin mRNA and synthesis, and a distinct effect of saturated and monounsaturated fatty acids on beta-cell turnover and function has been reported [117]. The etiology of IR is complex, and the endoplasmic reticulum (ER) appears to be implicated. The ER is the primary intracellular organelle responsible for protein folding, maturation, and trafficking [118]. The ER serves as a dynamic pool of calcium, and governs intracellular calcium homeostasis [119]. ER stress is defined as the accumulation of unfolded or misfolded proteins in the ER, which triggers an adaptive program called the unfolded protein response 
(UPR). Protein folding in the ER and production of ROS are closely linked events. In this context, the relationship between calcium and oxidative stress has been evoked [120]. Trace elements such as selenium and zinc might act as antioxidants. Zinc is important for insulin release as it is packed into co-crystals with insulin in the exocytotic vesicles. Zinc is released from insulin when it reaches the higher $\mathrm{pH}$ of blood, and zinc has recently been shown to negatively regulate $\alpha$-cell secretion [121]. Zinc, despite being redox-inert and therefore not itself an antioxidant, exhibits a variety of indirect antioxidant effects. On the other hand, zinc enhances the antioxidant capacity of the cell through direct competition with metals such as copper and iron that catalyze the Fenton reaction. Zinc depletion of the insulin molecule appears to leave insulin vulnerable to structural modifications, suggesting that the zinc in insulin may serve to protect it against oxidative damage. The relatively high levels of ROS and electrophiles produced by persistent hyperglycemia and hyperlipidemia, which typically accompany type 2 diabetes, result in $\beta$-cell dysfunction and glucose toxicity. the transient receptor potential (TRP) channel superfamily, which mediates $\mathrm{Ca}^{2+}$ influx in $\beta$-cells, is activated by oxidative stress [122].

\subsection{Adipose and skeletal tissue, insulin resistance and oxidative stress:}

Adipose tissue consists of a variety of cell types, including adipocytes, immune cells (macrophages and lymphocytes), preadipocytes, and endothelial cells. Adipokines, such as leptin and adiponectin, are secreted by adipocytes and these adipokines promote insulin sensitivity and the release of proteins, such as resistin [123] and retinol-binding protein 4 (RBP4), which impair insulin sensitivity [124] Adipokines such as adiponectin and adipocyte fatty acid binding protein (A-FABP) are prognostic biomarkers for cardiovascular disease and even promising therapeutic target for its treatment. 
Obesity and the associated increase in body fat mass are the consequences of long-term (months to years) positive energy balance. Pathways intrinsic to the cell can acutely detect or "sense" changes in energy balance or nutrient availability. Chronic activation of proinflammatory pathways within insulin target cells can lead to obesity-related IR. Elevated levels of the pro-inflammatory cytokines TNF- $\alpha$, IL-6, and CRP have been demonstrated in patients with IR and diabetes [125]. Peptides, including pro-inflammatory cytokines, chemokines and hormones can function in both an endocrine or paracrine mode in adipose tissue. In this field, TNF-a and IL-6 impair insulin signaling in insulin-sensitive tissues and raise IR [126].

Oxidative stress and IR are two intimately-linked processes. [111]. As we previously reported, p66ShcA was a gene that regulated the apoptotic responses to oxidative stress and it a major mediator of IR. P66shc has been shown to participate in insulin signaling and in particular to promote insulin-induced fat accumulation [32]. Although p66shc elicits the formation of oxygen species and increases cell oxidative stress in several pathophysiological settings. P66shc may operate as an adaptor molecule by participating in the assembly of supramolecular complexes relevant to the propagation of insulin signaling [127].

One of the targets of oxidative stress is the activation of multiple serine kinase cascades. These kinases are implicated in the insulin signaling pathway, including the insulin receptor (IR) and the insulin receptor substrate (IRS) family of proteins. It has been reported that $\mathrm{H}_{2} \mathrm{O}_{2}$ inhibited insulin-stimulated glucose transport [128, 129]. The activation of different pathways such as NF-kB, p38 MAPK, and JNK/SAPK appears sensitive to oxidative stress and linked to impaired insulin action, suggesting that they are associated with a role in oxidative stressinduced IR [128]. The relationship between the potent insulin sensitizing activity of adiponectin, the circulating proteins secreted from adipocytes and the inhibition of NF- $\mathrm{B}$ activation has been reported. Exposure of adipocytes to oxidative stress decreases anti- 
inflammatory adiponectin and increases pro-inflammatory adipocytokines [130]. Cellular protection by adiponectin is at least in part mediated by an antioxidative/nitrosative effect. Adiponectin reduces oxidative/nitrosative stress by inhibiting NADPH oxidase and iNOS expression [131, 132]. The relationship between oxidative stress and IR appears to be multifactorial. Involvement of a local renin-angiotensin aldosterone system (RAAS) has also been proposed as a potential mediator of oxidative stress to adipocytes [133].

In conclusion, adipose tissue inflammation is characterized by changes in immune cell populations giving rise to altered adipo/cytokine profiles, which in turn induces IR in skeletal muscle and the liver.

\subsection{Liver, insulin resistance and oxidative stress}

Following a meal, the intestine becomes the major source of glucose, which increases the availability of glucose to the pancreas. This, in turn, stimulates the pancreas to secrete insulin. One of the states of IR is characterized by the impairment of insulin-mediated suppression of hepatic glucose production. Therefore, IR individuals initially maintain normoglycemia by the overproduction of insulin by the pancreas. Long-term nd hypersecretion can lead to the dysfunction of pancreatic beta cells [134].

In the liver, macrophages are also key players in metabolic homoeostasis. Macrophages can be found in many tissues, where they respond to metabolic cues and produce pro- and/or antiinflammatory mediators to modulate metabolite program. Although it is evident that metabolic stress (e.g. fatty acids, ceramides and oxLDL/cholesterol) induces macrophage inflammation, the detailed mechanisms through which pro-inflammatory signaling pathways cause metabolic diseases, notably in the setting of IR, remain unclear. Resident macrophages in an organ such as the liver adapt to their local microenvironment and exhibit diverse functional and morphological phenotypes. Macrophages possess the ability to engulf and 
metabolize lipids and this way connect lipid metabolism with inflammation. Increased lipid deposition in the liver is also considered a factor in the pathogenesis of IR . Increased lipid accumulation in the liver is associated with increased FFA flux, which leads to the excessive accumulation of fatty acid intermediates such as ceramide. Lipid intermediates activate intracellular serine kinases, which can lead to the inhibition of insulin signaling. Rates of ceramide synthesis depend largely on the availability of long-chain saturated fats, which participate in the initial, rate-limiting step in de novo ceramide synthesis $[135,136]$. Ceramide induces the activation of ROS-generating enzymes, including NADPH oxidase, xanthine oxidase and NO synthase. In addition, ceramide has also been shown to interact with the mitochondrial electron transport chain, thereby leading to the generation of ROS [137]. In this field, early reports suggested that ceramide inhibited insulin activation of upstream signaling events. Manipulation of the enzymes that control sphingolipid synthesis or degradation in mice has a potent effect on IR and ameliorates lipotoxic responses associated with obesity. Ceramides contributed to IR. It has been suggested that in addition to ceramides, a number of other lipid intermediates may modulate insulin sensitivity [138]. Ceramide is now considered an important metabolite able to alter cellular metabolism and promote apoptosis. A major mechanism through which ceramide alters cellular metabolism is its dramatic inhibition of Akt, a serine/threonine kinase that is an obligate intermediate in the signaling pathway linking insulin and other growth factors to the expression, action, and subcellular distribution of nutrient transporters [139]. In this context, it has been suggested that inhibitors of ceramide synthesis or activators of ceramide degradation may provide new therapeutic options for diabetes [140]. 


\section{Antioxidant strategies to control oxidative stress in diabetes}

The complex and intimate association between increased oxidative stress and increased inflammation in related disorders such as type- 2 diabetes makes it difficult to establish the temporal sequence of the relationship $[141,142]$. In diabetic patients, the increase in oxidative stress is associated with a decline in cellular antioxidant defenses. Several attempts have been made to reduce oxidative stress-dependent cellular changes in patients with diabetes by antioxidant supplementation. The rationale for using certain vitamins and other compounds in the prevention and management of diabetes mellitus is based largely on experimental and epidemiologic studies. Various dietary compounds including long chain omega-3 fatty acids, antioxidants and pharmacological agents have the potential to modulate predisposition to inflammatory conditions. These components act through a variety of mechanisms that include decreasing the production of inflammatory mediator through effects on cell signaling and gene expression.

In this part of this review, we report that oxidative stress can be modified by enzymatic action (e.g., superoxide dismutase, thioredoxin, catalase, and glutathione peroxidase) and/or by nonenzymatic antioxidants, for example, vitamins (A, C, E), folate, glutathione, coenzyme Q10, $\alpha$-lipoic acid, carotenoids, flavonoids and trace elements $(\mathrm{Cu}, \mathrm{Zn}, \mathrm{Mg}$ and $\mathrm{Se}) . \mathrm{In}$ addition, we will highlight antioxidant compounds that show promise in improving vascular function in diabetic settings.

\subsection{Enzymatic antioxidants}

The hypothesis that by interrupting the overproduction of superoxide radicals and hydrogen peroxides it should be possible to normalize most alterations that contribute to metabolic 
dysfunction has been difficult to accomplish using conventional antioxidants. Antioxidants like vitamin E act on a one-to-one basis; while the hyperglycemia-induced overproduction of superoxide radicals is continuous. This has led to the use of catalytic antioxidants such as superoxide dismutase (SOD)/catalase (CAT) mimetics and functional mimics of glutathione peroxidase (GPx) [143, 144].

The role of ROS in the development of diabetic endothelial dysfunction has been underlined by a number of functional studies, demonstrating that diabetic blood vessels exhibit an improved endothelium-dependent relaxant response when treated with SOD. SOD entrappedliposomes restore the impaired endothelium-dependent relaxation of resistance arteries in experimental diabetes. One of the mechanisms relates to the fact that the reaction of NO with superoxide anion results in its inactivation and therefore induces a reduction in the biological availability of NO $[145,146]$. ROS not only reduce nitric oxide bioavailability but also facilitate the production and/or action of endothelium-dependent contracting factors [147]. New therapeutic drugs such as SOD-like mimics are being developed [148]. Metalloporphyrins, Mn cyclic polyamines, Mn salen derivatives and nitroxides have been synthetized as SOD mimics. The most potent mimics have been cationic meso $\mathrm{Mn}(\mathrm{III})-\mathrm{N}-$ substituted pyridylporphyrins and N,N'-disubstituted imidazolylporphyrins (MnPs) [149]. The metalloporphyrin-based SOD mimics had protective effects on the progression of T-cellmediated autoimmune diabetes. These results support the model of free-radical generation as a pathogenic mechanism in type 1 diabetes [150]. Although SOD and SOD mimetics have displayed efficacy in experimental models of diabetes, their role in improving the vascular complications of diabetes remains controversial in patients. This may be due to the fact that in pathological conditions, dismutation of superoxide by SOD is linked to the excess production of hydrogen peroxide, an oxidative agent known to cause irreversible endothelial damage. 
Increased understanding of the role of mitochondria and its enzyme, MnSOD, has motivated researchers to explore existing and new compounds for their ability to enter mitochondria and mimic MnSOD. Compounds such as MitoQ were developed to enter cells driven by plasma membrane potential, and mitochondria driven by mitochondrial membrane potential [151]. In MitoQ, a redox-cycling quinone, an analog of the ubiquinone of the mitochondrial electron transport chain, was coupled to a cationic triphenylphosphonium ion via long lipophilic alkyl chain [152]. An optimized MitoQ10 molecule, with a 10-carbon atom-alkyl chain, has the capacity to suppress mitochondrial oxidative stress, improving endothelial function [153].

CAT or GPx mimetics as a way to treat inflammation associated with the pathophysiology of many human disorders such as diabetes. One of the best studied GPx-like mimics is 2-phenyl1,2- benzisoselenazol-3(2H)-one, better known as ebselen or PZ51. Ebselen was one of the first selenium-based GPx mimics developed. Ebselen has been extensively studied for its therapeutic potential in various experimental models of diabetes. Gpx1-mimetics show promise as a targeted antioxidant approach and an alternative adjunct therapy to reduce diabetic complications [154].

The administration of trace elements and other antioxidants has been proposed as a therapeutic adjuvant in the treatment of diabetes $[155,156]$. Clinical trials have evaluated the use of nutritional supplements, such as selenium, in the prevention of cardiovascular and metabolic diseases, but these have yielded conflicting results (positive, neutral and negative). The treatment of diabetic rats with sodium selenite could protect the diabetic heart against dysfunction [157]. Several mechanisms are thought to mediate the biological effects of Se and these include a number of systems, and the synthesis and stability of metabolites that act as intermediates in the expression of diverse selenoprotein pathways and gene expression. 


\subsection{Non enzymatic antioxidants}

Non-enzymatic antioxidants are represented by ascorbic acid (Vitamin C), tocopherol (Vitamin E), glutathione (GSH), carotenoids, flavonoids, and other antioxidants. Under normal conditions, there is a balance between the activities and the intracellular levels of these antioxidants.

\subsubsection{Antioxidant vitamins}

\section{Vitamin C}

Vitamin C (ascorbic acid) is an essential cofactor for $\alpha$-ketoglutarate-dependent dioxygenases, such as prolyl hydroxylases, which play a role in the biosynthesis of collagen and in the down-regulation of hypoxia-inducible factor (HIF)-1, a transcription factor that regulates many genes responsible for tumor growth, energy metabolism, and neutrophil function and apoptosis [158]. Vitamin $\mathrm{C}$ has an important role in the immune function and various oxidative/inflammatory processes, such as scavenging ROS and RNS, preventing the initiation of chain reactions and protecting cell membranes against lipid peroxidation. The oxidized products of vitamin $\mathrm{C}$, ascorbyl radical $[23,159,160]$ and dehydroascorbic acid, are easily transformed back to ascorbic acid by glutathione, NADH, or NADPH. Ascorbate can recycle vitamin $\mathrm{E}$ and glutathione back from their oxidized forms. Vitamin $\mathrm{C}$ might be used as a therapeutic agent against the oxidative stress in DM patients. Trials assessing the effect of vitamin C supplementation on various markers of DM have yielded inconsistent results [161]. 


\section{Vitamin E}

Vitamin E refers to a group of compounds that include tocopherols and tocotrienols. Alphatocopherol is the most abundant and biologically active. As for its mechanism of action, vitamin $\mathrm{E}$ is a potent lipophilic antioxidant. It is able to neutralize free radical species produced during normal cellular metabolism, thus protecting cellular membranes [162] and lipoproteins. The interaction of vitamins E and C has led to the idea of "vitamin E recycling", whereby the antioxidant function of oxidized vitamin $\mathrm{E}$ is continuously restored by other antioxidants. This "antioxidant network" depends on the supply of aqueous antioxidants and the metabolic activity of cells. Free metals, such as iron or copper, can reinitiate lipoperoxydation by reaction with peroxides to form an alkoxy radical [158]. Low levels of vitamin $\mathrm{E}$ are associated with the increased incidence of diabetes, suggesting that patients with diabetes have decreased levels of antioxidants. In addition, diabetic patients may also have greater antioxidant requirements because of the increased hyperglycemia-related free radical production. Improvement in glycemic control decreases markers of oxidative stress, as does vitamin E supplementation. In 2007, a review focused [163] on a number of small trials showed that vitamin E had beneficial cardiovascular effects.

Clinical trials on a larger scale include the Heart Outcomes Prevention Evaluation (HOPE) trial and Secondary Prevention with Antioxidants of Cardiovascular Disease in End Stage Renal Disease (SPACE) [164]. Further long-term clinical trials with a large patient population are needed to assess whether vitamin E supplementation to diabetic patients lowers the incidence of the development and progression of complications, such as retinopathy, nephropathy, and neuropathy. The overwhelming consensus from these studies is that vitamin E supplementation does not provide cardiovascular benefits [165-168]. In contrast, a metaanalysis of these studies suggested that high-dose vitamin E supplementation may increase mortality [167], and several opinion articles have called for a moratorium on the prescription 
of high-dose vitamin E supplements [169]. A possible explanation for the failure of these studies in spite of solid preclinical data is the inadequate nature of patient selection. Inflammation rather than oxidative stress may be the principal contributor to diabetic vascular dysfunction. In agreement with this concept is the finding that endothelial function improves in type 2 diabetic patients treated with rosiglitazone, an agent that reduces inflammation but not oxidative stress [170]. These findings may partially explain the inconsistent and mostly disappointing results with antioxidant use in diabetic patients [171]. A pharmacogenomic strategy of screening DM individuals for the Hp genotype and treating those with Hp 2-2 with vitamin E appears to be highly clinically effective [172].

\section{Folic acid}

Folic acid (vitamin B9) is widely used to lower homocysteine concentrations and prevent adverse cardiovascular outcomes. However, the effect of folic acid on cardiovascular events is not clear. The influence of folic acid on diabetes has also been investigated. In a recent study, it was reported that folic acid supplementation decreased plasma levels of homocysteine and improved glycemic control, IR and folate and B12 levels in type 2 diabetic patients treated with high doses of metformin [173]. A systematic review and meta-analysis to assess the effects of folic acid supplementation on cardiovascular outcomes has been recently published. [174]. The findings of this study suggested that folic acid supplementation had no significant effects on major cardiovascular events, stroke, myocardial infarction or all-cause mortality. Furthermore, high-dose folic-acid supplementation may increase the risk of cancer cell growth and impair renal function. Importantly, folic acid and B vitamins are water-soluble and excreted by the kidney; therefore, therapy toxicity may be of great concern in patients with impaired renal function. 


\subsubsection{Non-vitaminic antioxidants}

\section{N-Acetylcysteine}

Among chronic diseases, diabetes mellitus is the most common cause of peripheral neuropathy (PN). The oral administration of $\mathrm{N}$-acetylcysteine (NAC), a biosynthetic precursor of GSH, to streptozotocin-diabetic rats resulted in the prevention of diabetes-induced deficits such as PN. Motor nerve conduction velocity was shown to be significantly decreased by diabetes; NAC inhibited the atrophy of myelinated fibers [175]. In another study, experimentally-induced diabetes for two months in rats resulted in a $48 \%$ reduction in endoneurial blood flow; this effect was corrected by NAC supplementation [176]. Clinical studies are warranted to determine applications for NACs in the treatment of diabetic PN [177]. Another deleterious effect of diabetes is platelet hyperaggregability. Platelet hyperaggregability is a pro-thrombotic feature of type- 2 diabetes, associated with low levels of the antioxidant glutathione (GSH). The clinical delivery of NAC may help redress a GSH shortfall in platelets, thereby reducing thrombotic risk in type-2 diabetes patients [178].

\section{Lipoic acid}

Alpha-lipoic acid (ALA) is a dietary supplement and a therapeutic agent. It modulates redox potential because of its ability to equilibrate between different subcellular compartments as well as extracellularly. Both the oxidized (disulphide) and reduced (di-thiol: dihydro-lipoic acid, DHLA) forms of ALA show antioxidant properties. ALA and DHLA scavenge hydroxyl radicals, hypochlorous acid and singlet oxygen [179]. In our laboratory, we also observed that DHLA was able to diminish the superoxide-driven oxidation of a sensitive spin probe, in a manner comparable to that of superoxide dismutase [180]. It has the ability to directly quench ROS in biological systems. ALA as a potent chelator of divalent metal ions also exerts antioxidant effects by acting on transition metal chelation. The ALA/DHLA redox couple 
enhances both the antioxidant defenses and the function of endothelial cells, thus preserving nitric oxide-dependent vascular relaxation in humans [181]. The interaction between LA and regulatory components of the insulin signaling cascade has proved functionally beneficial to skeletal muscle glucose uptake, whole-body glucose tolerance, and helpful against IR resistance in animal models [182].

Given its potential antioxidant properties, the possible health benefits of ALA supplementation have been tested in patients suffering from cardiovascular and metabolic diseases such as diabetes. DM is associated with the overproduction of ROS and chronic inflammation. IR plays a significant role in the physiopathology of the vasculature. ALA possesses a number of beneficial effects both in the prevention and in the treatment of diabetes in several experimental conditions. The results in patients are contradictory [179]. In addition, in some studies, ALA presented beneficial effects in the treatment of symptomatic diabetic neuropathy, which is a major health problem. [183]. At the moment, it is agreed that antioxidants such as lipoic acid provide no established benefit in the management of diabetic complications.

\section{Coenzyme Q10}

CoQ10, or ubiquinone, is a lipid-soluble benzoquinone with a side-chain of 10 isoprenoid units endogenously synthesized in the body from phenylalanine and mevalonic acid. The fundamental role of CoQ10 in mitochondrial bioenergetics and its well-acknowledged antioxidant properties constitute the basis for its clinical applications. Its enzymatic processes facilitate electron transfer in the generation of adenosine triphosphate (ATP). A small increase in the concentration of coenzyme Q10 in mitochondrial membranes can lead to an increase in mitochondrial respiration. This observation may be the biochemical mechanism by which exogenous coenzyme Q10 has in some studies improved mitochondrial dysfunction. In 
diabetes, the uncoupling of oxidative phosphorylation may also occur at the mitochondrial level as a consequence of hyperglycemia and elevated fatty acids. CoQ supplementation may also act synergistically with anti-atherogenic agents to improve endothelium function in diabetes. CoQ may also improve endothelial dysfunction by 'recoupling' eNOS. CoQ10 supplementation improved endothelial dysfunction in statin-treated type 2 diabetic patients, possibly by altering local vascular oxidative stress [184]. The experimental and clinical studies on the effects of CoQ supplementation in diabetes require testing in clinical endpoint trials that include patients within the wider spectrum of metabolic syndrome. CoQ10 does not induce serious adverse effects in humans and new formulations have been developed that improve absorption [185].

\section{Mitochondria-targeted antioxidants}

Mitochondria produce large amounts of free radicals, and mitochondrial oxidative damage can contribute to a range of degenerative conditions including CVDs. There is abundant evidence suggesting that mitochondrial dysfunction is a main cause of IR and related cardiometabolic comorbidities. Consequently, the selective inhibition of mitochondrial oxidative damage is an obvious therapeutic strategy. Current strategies for delivering drugs to the mitochondria fall into two categories: active and passive targeting. A high number of antioxidants have been successfully targeted to mitochondria. MitoQ, which consists of a ubiquinone moiety linked to a triphenylphosphonium by a ten-carbon alkyl chain, is the most studied and widely used mitochondrial antioxidant [186]. Mitochondria-targeted molecules and their therapeutic potential have been described. XJB-5-131 is an ROS scavenger containing the Leu-D-Phe-Pro-Val-Orn fragment of gramicidin S, a membrane-active cyclopeptide antibiotic [187]. Mitochondria-targeted antioxidant peptides such as compounds XJB-5-131 or SS31 could be potential new treatment for diabetic diseases [188]. 


\subsubsection{Sequestration of metal ions such as iron}

Redox active metals like iron $(\mathrm{Fe})$, copper $(\mathrm{Cu})$, chromium $(\mathrm{Cr})$, cobalt $(\mathrm{Co})$ and other metals undergo redox cycling reactions and possess the ability to produce ROS and NO in biological systems. The homeostasis of iron results from a tightly coordinated regulation by different proteins involved in the uptake, excretion and intracellular storage/trafficking of iron. The redox state of the cell is predominantly dependent on an iron (and copper) redox couple and is maintained within strict physiological limits. Through the Fenton reaction, iron can generate various reactive oxygen or nitrogen species. Dysfunctions in the metabolism of iron lead to several chronic diseases.

Oxidative stress is one of the major causative factors of diabetes. iron plays a pathogenic role in the complications of diabetes such as microangiopathy and atherosclerosis [189]. However, reliable methods need to be developed to measure the "free" iron implicated in the initiation and development of tissue injury. Iron chelation therapy may be a novel way to interrupt the cycle of catalytic iron-induced oxidative stress and tissue injury. Desferoxamine prevents diabetes-induced endothelial dysfunction. Randomized clinical trials of new agents such as deferiprone and deferasirone are needed to determine their effectiveness in treating/preventing diabetes and its complications [190]. Mutations in superoxide dismutase enzymes and ironuptake regulator may lead to excess levels of superoxide anion radicals and iron overload. New trends in clinical practice are towards combined chelation therapy treatments. Structurally different chelators in order to achieve the more effective removal of toxic metals are being studied. [191]. Clinical testing of several low-molecular-weight compounds that target oxidant/redox signaling, or quench oxidants and reactive aldehydes are currently being conducted. Lazaroids (21-aminsteroids, U75412E or tirilazad mesylate) are a group of nonglucocorticoid analogs of methylprednisolone which are able to penetrate hydrophobic 
regions of the cell membrane, specifically to prevent peroxidation of membrane lipids in tissues [192].

\subsubsection{Physiological approach: exercise}

Exercise produces a short-term inflammatory response that increases oxidative stress, and plasma levels of CRP, but this pro-inflammatory response is followed by a long-term antiinflammatory effect. It has been demonstrated that regular exercise reduces CRP, IL-6, and TNF- $\alpha$ levels and also increases anti-inflammatory substances such as IL-4 and IL-10. It is generally believed that even short-term endurance exercise training results in rapid increases in Mn-SOD and GPx activity in different tissues such as the liver, kidney, heart and skeletal muscle [193].

Regular exercise has a beneficial effect on the correction of risk factors for diabetes mellitus. Similarities between the effects of chronic exercise and a putative antidiabetic polypill were highlighted, though exercise, when practiced regularly, was shown to be better [194, 195].

\subsection{Therapeutic approaches with classical agents:}

The effect of the two most prescribed antidiabetic drugs: metformin and glibenclamide, on oxidative stress associated with diabetes were examined. Various antioxidant effects due to their indirect actions were reported; for example: the ability of these drugs to activate different pathways such as AMPK-mediated signaling. The AMPK pathway reduces the ROS level by FOXO3, and subsequently upregulates the expression of thioredoxin [195]. One study investigated the incidence of hyperglycemia induced by honey as an adjunct to metformin and/or glibenclamide in relation to the activities of antioxidant enzymes and other markers of oxidative stress in the kidneys of streptozotocin (STZ)-induced diabetic rats. The 
data suggested that metformin or glibenclamide, when administered alone, might not effectively arrest oxidative stress-mediated damage in the kidneys of diabetic rats [196]. The up-regulation of cardiac adiponectin induced by metformin could explain the beneficial effects of this drug [197]. Thus, an ideal therapy for diabetes mellitus would be a drug that not only possesses antihyperglycemic effect, but also enhances or protects the antioxidant defense system.

\subsection{Therapeutic approaches with new agents (Figure 4)}

\subsubsection{Edaravone}

Edaravone (3-methyl-1-phenyl-2-pyrazolin-5-one) is a potent free-radical and carbonyl scavenger and inhibitor of lipid peroxidation [198, 199]. The effect of edaravone on diabetes has been examined in multiple low-dose STZ-treated mice [200]. Mice treated with low-doses of STZ for five consecutive days showed progressive hyperglycemia and an increased incidence of diabetes. Daily treatment with edaravone during the STZ injections counteracted the multiple low-doses STZ-induced-hyperglycemia in a dose-dependent manner. Multiple low-dose streptozotocin treatment also increased the lipid peroxidation product thiobarbituric acid reactive substance in pancreatic tissues of mice, and this effect was completely inhibited by edaravone. These findings suggest that edaravone counteracts the development of STZinduced diabetes by scavenging free radicals.

\subsubsection{Benfotiamine}

One new class of potential therapeutic agents is transketolase activators. In diabetes, the concentration of glycolytic intermediates is high, transketolase could reduce their concentration. This enzyme requires the vitamin thiamin as a cofactor. The thiamin derivate benfotiamine activates this transketolase in endothelial cells [201]. The beneficial effects of 
benfotiamine on complication-causing pathways in rodent models of diabetes have been demonstrated [202]. In different kidney cell lines, benfotiamine prevented oxidative stress induced by mutagen4-nitroquinoline-1-oxide (NQO), uremic toxin indoxyl sulfate, and angiotensin II. Cell-free experiments showed a direct antioxidant effect of benfotiamine, which might account for the protective effect. Oxidative DNA damage, induced by angiotensin II, was completely prevented by benfotiamine. Treatment with high-dose thiamin reduced albuminuria in patients with type 2 diabetes [203].

\subsubsection{Poly(ADP-ribose) polymerase inhibitors (PARP inhibitors)}

PARP-1 regulates the expression of various proteins such as inducible nitric oxide synthase (iNOS), intracellular adhesion molecule- 1 (iCAM-1) and COX-2 at the transcription level and has been linked with the development of inflammatory cell injury. Oxidative stress generates DNA strand breaks, which in turn activate PARP. PARP activation potentiates NF$\kappa \mathrm{B}$ activation and AP-1 expression, resulting in greater expression of $\mathrm{AP}-1$ and NF- $\mathrm{B}-$ dependent genes such as iNOS and iCAM-1 [204]. ROS and RNS are generated in cardiomyocytes and endothelial cells during diabetic complications and other CVD. These reactive species induce oxidative DNA damage and consequent activation of the nuclear enzyme poly(ADP-ribose) polymerase 1 (PARP-1), the most abundant isoform of the PARP enzyme family. PARP overactivation modulates important inflammatory pathways, and PARP-1 activity can also be modulated by several endogenous factors such as kinases, polyamines and hormones (estrogen). pharmacological inhibition of PARP provides significant benefits in animal models of cardiovascular disorders, and novel PARP inhibitors have entered clinical development for various cardiovascular indications [205].

The development of a PARP-1-deficient mouse has allowed the direct examination of the role of PARP-1 in diabetes. However, the use of PARP inhibitors has shown that this enzyme is 
implicated in the development of diabetes and beta-cell destruction. In this area, many of the inhibitors used have been shown to have additional actions besides inhibition of PARP. These include hydroxyl radical and hydrogen peroxide scavenging activities along with inhibition of iNOS expression and activity [206, 207]. Given that chronic neuropathic pain may occur in diabetic patients, treatments involve heavy pharmacological approaches. Pharmacological therapeutic options include agents that may hold some promise such as poly (adenosine diphosphate-ribose) polymerase inhibitors [208, 209]. After treatment with PARP inhibitors, increases in nuclear translocation of $\mathrm{NF}-\kappa \mathrm{B}$ and the expression of Bax were significantly reduced in diabetic rat bladders [210]. These results suggest that activation of $\mathrm{NF}-\kappa \mathrm{B}$ pathways promote apoptosis via an increase in Bax expression in diabetic rat bladders. However, the exact mechanisms involved in NF- $\kappa \mathrm{B}$ activation, which in turn increases Bax expression remain unclear. Recent findings support an important role for PARP activation in diabetic peripheral neuropathy and kidney hypertrophy associated with diabetes, and provide a rationale for the development and further studies of PARP inhibitors, for the prevention and treatment of these complications [208]. 


\subsubsection{Peroxynitrite decomposition catalysts}

In normal vascular physiology, endothelium-derived nitric oxide (NO) is one of the most potent endogenous vasodilators and, because of its anti-inflammatory, anti-proliferative and anti-thrombotic properties, it is an endogenous vasoprotective agent in diabetes [211]. Indeed, endothelial dysfunction with reduced NO production and/or bioavailability in high-risk patients with diabetes may contribute to the development and progression of vascular complications in these pathologies. However, high amounts of NO produced by inducible NO synthase (iNOS) and/or peroxynitrite $\left(\mathrm{ONOO}^{-}\right)$resulting from the interaction between $\mathrm{NO}$ and superoxide anion are involved in the development of pro-inflammatory reactions, tissue damage and organ dysfunction [212].

Broad antioxidant properties and the ability to scavenge superoxide, lipid peroxides, $\mathrm{ONOO}^{-}$, and $\mathrm{H}_{2} \mathrm{O}_{2}$ have been attributed to the metalloporphyrin-based catalytic antioxidant, MnTE-2PyP [Manganese (III) Meso-Tet- rakis-(N-methlypyridinium-2-yl) porphyrin] [213]. Over the last decade, a number of peroxynitrite decomposition catalysts (e.g. the metalloporphyrinic compounds FP-15, FeTPPS and FeTMPS) have been tested in a variety of experimental models of diabetic complications. Elevated glucose increased the formation of ONOO, which contributes to the induction of renal COX-2 in the diabetic rat. FeTMPyP treatment of diabetic rats reduced the elevated creatinine clearance and urinary excretion of TNF- $\alpha$ and transforming growth factor (TGF)- $\beta$, suggesting a renoprotective effect. The results of these studies demonstrated that peroxynitrite neutralization reduced the development of diabetic endothelial dysfunction and CVD [214, 215].

\subsection{Other pharmacological approachs}

Another strategy for modulating oxidative stress in humans is via exploitation of the pleiotropic properties of drugs directed primarily at pathologies, these drugs being indirect 
antioxidants. The ideal approach to antioxidant therapy requires stimulation of NO production and simultaneous inhibition of vascular superoxide production. Drugs such as statins [216218], angiotensin-converting enzyme inhibitors (ACEI) [26], and AT1-receptor blockers, possess such combined antioxidant properties [219].

\subsubsection{Angiotensin-converting enzyme inhibitors (ACEI)}

Angiotensin II has long been known to increase vascular smooth muscle $\mathrm{O}_{2}{ }^{\bullet-}$ production by activation of a membrane-bound $\mathrm{NAD}(\mathrm{P}) \mathrm{H}$ oxidase. On the other hand, many studies of the role of the renin-angiotensin-aldosterone system (RAAS) in modulating glucose homeostasis have focused on insulin sensitivity [220]. There are different mechanisms by which ACEI may exert protective cardiovascular effects via the reduction and/or prevention of oxidative stress: 1) reduction of NADPH oxidase activity 2) Ang II is cleaved to Ang-(1-7) by ACE2, thereby attenuating Ang II induced actions 3) the production of NO is potently induced by Ang-(1-7), which might protect against endothelial dysfunction and oxidative stress [221, 222].

Activation of the RAAS and subsequent signaling through AT1 receptors appear to contribute to the development of diabetic cardiomyopathy. Angiotensin converting enzyme (ACE) inhibitors improve the outcome of heart failure in patients with diabetes [223].

ACEIs and angiotensin II receptor blockers (ARBs) are the preferred therapies for hypertension, but invariably, a combination therapy with additional drugs can exacerbate the glycaemia of metabolic syndrome [224]. Activation of the RAAS with free radical production in perivascular adipose tissue may contribute to the vascular RAAS and influence vascular function [133]. Perivascular adipose tissues release a variety of substances that affect vascular tone and the infiltration of inflammatory cells. The mechanisms that control adipokine secretion from perivascular adipose tissue remain to be determined. As this adipose tissue is 
located within insulin target tissues, it may well contribute to the pathogenesis of type 2 diabetes [225].

\subsubsection{Peroxisome proliferator-activated receptors (PPARs) such as thiazolidinediones}

PPARs are already considered an attractive therapeutic target for the treatment of metabolic disorders. PPAR $\gamma$ agonists were shown to effectively attenuate oxidative stress, inflammation and apoptosis. PPARs play a key role in regulating whole body glucose homeostasis and insulin sensitivity. Although these receptors are expressed most highly in adipose tissues, they are also present at lower levels in many tissues. Cytosolic fatty-acid-binding protein 4 (FABP4) provides the solubility and intracellular trafficking of long-chain fatty acids and other hydrophobic ligands. FABP4 is expressed in adipocytes, macrophages that infiltrate tissue beds, and skeletal muscle tissues. It is regulated by peroxisome proliferator-activated receptor- $\gamma$ (PPAR- $\gamma$ ) agonists, insulin, and fatty acids [226]. Activators of PPAR $\alpha$ (fibrates) and PPAR $\gamma$ (thiazolidinediones or glitazones) antagonize angiotensin II effects in vivo and in vitro and have cardiovascular antioxidant and anti-inflammatory actions.

Several preclinical and clinical studies indicate that PPAR agonists exert a protective effect in the treatment of vascular dysfunctions [227-229]. While it has been established that PPAR $\gamma$ compounds such as troglitazone and pioglitazone favorably alter lipid metabolism, as well as reduce inflammation, their effects on neurovascular inflammation are only modest. In contrast, PPAR $\alpha$ agonists reduce fatty acids in plasma and cause a reduction in atherogenic LDL and triglyceride levels, as well as an increase in HDL-C [230]. PPARs have also been shown to decrease the expression of adhesion molecules ICAM-1 and VCAM-1. Furthermore, impaired vascular reactivity in diabetics was associated with elevated levels of VCAM-1. Moreover, PPARs also have negative effects on macrophage function, by inhibiting the 
production of the inflammatory cytokines TNF- $\alpha$, IL1- $\beta$ and IL- 6 and it has been reported that levels of TNF- $\alpha$ and IL-6 are raised in diabetic conditions [231].

Thiazolidinediones (TZDs), a major class of insulin-sensitizing drugs, are synthetic PPAR $\gamma$ ligands that promote the transcriptional activity of this nuclear receptor. TZDs increase insulin sensitivity and to have an antioxidative effect. PPAR $\gamma$ has a wide range of functions, but concerning insulin sensitivity, it is known to promote lipogenesis and adipocyte differentiation and to reduce the level of circulating free fatty acids. TZDs protected pancreatic beta-cells from oxidative stress, this effect being dependent largely on PPAR $\gamma$. In addition, the expression of catalase is increased by TZDs [232]. Vitamin E induced adiponectin expression indirectly through the upregulation of PPAR $\gamma$ expression as well as increased 15d-PGJ2 levels. These two elements appear to work synergistically to enhance adiponectin expression [233, 234].

Pioglitazone improves arterial stiffness and CRP levels in diabetes independent of changes in glycemic control [235]. The anti-oxidant balance in pioglitazone-treated hearts was significantly bolstered by reduced (NADPH) oxidase (Nox1 and p22(phox) sub-units activity and the preservation of manganese SOD activity [236].

PPAR- $\alpha$ agonists are used as adjunct therapy in the treatment of diabetes. Fibrates act on PPAR- $\alpha$ to reduce the level of hypertriglyceridemia. PPAR- $\alpha$ agonists are used in the treatment of diabetes type 2 , as well as in the treatment of retinopathy associated with diabetes type 1 because of its ability to improve the lipid profile [237]. In vivo, fibrates increase levels of fatty acid binding proteins (FABPs) through both enhanced transcription and enhanced mRNA stability. The modulation of L-FABP expression could be beneficial during periods of cellular oxidative stress associated with diabetes. L-FABP is an important member of the hepatocellular antioxidant defense system, reducing ROS levels during periods of oxidative stress [238]. Adipocyte/macrophage fatty acid binding protein (A-FABP)is 
closely associated with metabolic syndrome, obesity and the development of atherosclerosis and diabetes [239].

\subsection{Promising new clinical agents:}

\subsubsection{FGF21}

It is very important to develop new compounds that target key vascular ROS producing enzymes and mimic endogenous antioxidants. This strategy may prove clinically relevant in preventing the development and/or retarding the progression of diabetes-associated vascular complications. As regulators of lipid and glucose metabolism, PPARs such as such as fibroblast growth factor 21 (FGF21) are of great interest [240]. FGF21 expression is induced in white adipose tissue by PPARgamma. FGF21 is a promising new clinical candidate for the treatment of IR and other aspects of metabolic syndrome [241, 242]. FGF21 enhances mitochondrial function and oxidative capacity via activation of AMPK and SIRT1 in adipocytes. Consequently, these changes improve insulin sensitivity and its beneficial metabolic effects underscore the potential of FGF21 as a therapeutic agent for obesity and type 2 diabetes [243].

\subsubsection{Epoxide hydrolase inhibitors}

Soluble epoxide hydrolase (sEH, EPHX2) inhibitors effectively increase levels of epoxyeicosatrienoic acids (EETs) and reduce levels of dihydroxyeicosatrienoic acids, which may be translated to a therapeutic potential in many disease indications such as diabetes. Chalcones (1,3-diaryl-2-propen-1-ones) and their heterocyclic analogues belong to the flavonoid family. These compounds, naturally found in plants or of synthetic origin, are known to exhibit several biological activities. Chalcones isolated from plants have insulin-like activities and improve glucose uptake in adipocytes. Chalcones stimulate glucose uptake and 
potentiate insulin-stimulated glucose uptake in adipocytes [244, 245]. Hydroxychalcones (2',5'-dihydroxychalcone: 2',5'-DHC ) are naturally occurring compounds with a therapeutic interest because of their anti-inflammatory and antiangiogenic properties. They inhibit the synthesis of inducible NO synthase and to induce the expression of heme oxygenase-1 (HO-1) $[246,247]$. The potential involvement of Nrf2 signaling has been demonstrated in both the anti-inflammatory and the antioxidant activities elicited by a chalcone derivate: LicochalconeE. This compound induces nuclear translocation of Nrf2, ARE-promoter activation and the transcription of cytoprotective HO-1 in vitro and in vivo [248]. The most studied targets for sEH inhibitors are related to the reduction of inflammation, and these compounds, including one Phase II clinical candidate, appear promising [249]. A direct link between sEH and glucose homeostasis exists. Disrupting the Ephx2 gene or inhibiting its EH activity leads to improved systemic insulin sensitivity and enhanced glucose tolerance [250].

\subsubsection{Incretin mimetics and inhibitors of their metabolism}

Two gut peptides, glucose-dependent insulinotropic polypeptide (GIP: gastric inhibitory polypeptide) and glucagon-like peptide-1 (GLP-1) are widely recognized for their role as incretins, and mediate the increase in insulin secretion. The enzyme dipeptidyl peptidase-4 (DPP-4) rapidly degrades GLP-1 and GIP to their inactive metabolites. Competitive inhibition of DPP-4 increases the half-life and bioavailability of active incretin hormones, enhancing their biological effect. The incretin effect has been estimated to account for 50-70\% of total postprandial insulin secretion, which was primarily considered a response to oral glucose [251]. The development of novel anti-diabetic interventions that enhance endogenous incretin secretion appears to be an attractive therapeutic strategy. Both GLP-1 and GIP receptors are expressed on pancreatic alpha and beta-cells. Moreover, plasma GLP-1 levels were found to be lower in type 2 diabetic patients than in non-diabetic controls [252]. 
Incretin-based therapies for diabetes mellitus include GLP-1 receptor agonists (which are resistant to DPP-4 degradation) and DPP-4 inhibitors [253]; the mechanisms of action of both involve the potentiation of the endogenous effects of GLP-1 [254, 255]. DPP-4 inhibitors include sitagliptin, saxagliptin, linagliptin, vildagliptin and alogliptin [256]. In clinical practice, GLP-1 receptor agonists/analogues, such as exenatide, exendin-4 and liraglutide, are approved for the treatment of type-2 diabetes [257]. Recently, the protective properties of GLP-1 and liraglutide in endothelial cells have been demonstrated. GLP-1 reduced TNFalpha-mediated expression of adhesion molecules in human umbilical vein endothelial cells (HUVECs) [189], while pretreatment with liraglutide for 30 min could inhibit ROS generation in HUVECs exposed to TNF-alpha. Moreover, TNF-alpha-mediated upregulation of NADPH oxidase subunits gp91phox and p22phox was significantly reduced by liraglutide to the same levels as control HUVECs cultured in the absence of TNF-alpha. The results of this study suggest that liraglutide has pivotal antioxidant and anti-inflammatory effects on endothelial cells in concentrations that are biologically relevant [258].

Exendin- 4 has been reported to prevent the generation of ROS in INS-1 cells (a pancreatic beta-cell line) and in the liver [259]. In metformin-treated patients with type 2 diabetes, exenatide showed beneficial effects on postprandial glycaemia and lipidaemia. These effects were associated with better changes in oxidative stress markers such as malonedialhehyde and oxLDL during one year of treatment as compared to insulin Glargine [260].

\subsubsection{Inhibitors of ceramide synthesis or activators of ceramide degradation and} sphingosine modulators

Inhibitors of ceramide synthesis or activators of ceramide degradation may provide new therapeutic options for diabetes. Sphingosine kinases (SKs: SK1 and SK2) are promising new therapeutic targets because they regulate the balance between pro-apoptotic ceramides and 
mitogenic sphingosine-1-phosphate. However, several small molecule inhibitors of SKs have been described in the literature [140]. Fingolimod (FTY720) is a first-in-class, orally active, sphingosine 1-phosphate (S1P)-receptor modulator with a structure closely related to sphingosine. The compound was discovered by the chemical modification of a natural product, myriocin. The phosphorylated form of FTY720 acts as a functional antagonist at S1P receptor type 1, inhibits lymphocyte egress from secondary lymphoid organs and shows immunomodulating effects [261]. The partial inhibition of glucosylceramide biosynthesis, and subsequent glycosphingolipids, not only restores insulin sensitivity of adipocytes in Lep ${ }^{O b}$ mice, but also improves adipocyte function and consequently reduces the number of macrophages and local inflammation [262]. Importantly, inhibition of de novo ceramide synthesis with myriocin has an effect on whole-body energy metabolism and is sufficient to reverse obesity-induced whole-body glucose intolerance and IR [263].

\subsubsection{P66Shc/RAGE signaling: a key effector and possible target}

The persistence of hyperglycemic stress despite glucose normalization has been defined as "hyperglycemic memory". It was postulated that ROS may be critically involved in the persistence of hyperglycemic stress in endothelial cells and experimental diabetes. In the last few years, several studies have identified critical molecular determinants of vascular hyperglycemic memory. In this context, it has been evoked the possible role of p66Shc, the modulator of intracellular redox state; its downregulation reverses the pathological features of hyperglycemic memory in vascular tissues. Increased AGE formation has been considered a key factor underlying the glycemic memory [264]. Soluble forms of AGE receptors (sRAGEs) bind ligands including AGEs and can antagonize RAGE signaling, thus prospecting an interesting therapeutic option to reverse hyperglycemic memory. In this 
context, the ligand families of RAGE, such as amphoterin, S100/calgranulin family and highmobility group box 1 (HMGB1), were investigated [265].

Interestingly, recent results suggest that p66Shc controls methylglyoxal levels and it exists a link between p66Shc and the methylglyoxal/AGEs pathway; methylglyoxal, a dicarbonyl metabolite, being a major precursor of AGEs [35]. These data, together with earlier findings, point cellular events that link p66Shc to AGE-pathway-responses and represent therapeutic targets. It is well-established that blockade or genetic deletion of RAGE suppresses acceleration of vascular disease and inflammation [266]. Metformin may protect against tubular cell injury in diabetic nephropathy by blocking the AGEs-RAGE-ROS axis [267].

\section{Conclusions}

In type 2 diabetic patients, oxidative stress induced by the presence of excessive ROS and RNS is closely associated with chronic inflammation leading to potential tissue damage. The role of oxidative stress in the development of diabetic endothelial dysfunction is underlined by a number of studies. The development of inhibitors against the main sources of ROS generation could be an alternative approach to conventional antioxidant therapies. One of the main challenges of research in recent years has been finding ways to attenuate oxidative stress in order to improve diabetes. However, the lack of evidence to prove the beneficial effects of antioxidant vitamins in the prevention of several oxidative-stress-related diseases has led to the development of new strategies, for example target antioxidants to mitochondria. The angiotensin II system is another factor to be considered in the process of diabetic endothelial dysfunction. As discussed above, ROS produced following angiotensin II-mediated stimulation of NADPH oxidases can exert direct oxidative effects and induce peroxynitrite 
formation. On the other hand, it is not clear whether or not the benefits of antioxidant supplementation depend on baseline antioxidant status, because currently there are no reliable biomarkers of oxidative stress suitable for large population studies.

In conclusion, as regards therapy, it appears important to develop new compounds that target key vascular ROS-producing enzymes and mimic endogenous antioxidants. This strategy may prove clinically relevant in preventing the development and/or retarding the progression of diabetes-associated vascular complications. 


\section{Abbreviations:}

ACS, Acute coronary syndrome; A-FABP, Adipocyte fatty acid binding protein; ADMA, asymmetric dimethylarginine; AGE, Advanced glycation end-products; AP-1, activator protein 1; ARE, antioxidant response element; AT, angiotensin; ATF4, Activation transcription factor 4; Bach-1, cap'n'collar (CNC) homology 1; $\mathrm{BH}_{4}$, tetrahydrobiopterin; CAT, catalases; COX, cyclooxygenases; ER, Endoplasmic reticulum; ERK, extracellular signal-regulated kinase; FAD, flavin adenine dinucleotide; FFA, Free fatty acid; FMN, flavin mononucleotide; FOS, Finkel-Biskis-Jinkins osteosarcoma; FOXO, forkhead protein; GAPDH, glyceraldehyde-3-phosphate dehydrogenase; GPx, glutathione peroxidases; GSH, glutathione; GSH, glutathione; GSSG, oxidized glutathione; GP, glutathioneperoxidase; GTP, guanosine triphosphate; GTP-CH, GTP cyclohydrolase 1; HDL, High-density lipoprotein; HO-1, heme oxygenase-1; HHE; 4-hydroxyhexenal; HIF, Hypoxia-inducible factor; HNE, 4hydroxynonenal; HSP, heat shock protein; iCAM-1, intracellular adhesion molecule- 1; IGFBP1, insulin-like growth factor binding protein-1; IR, insulin resistance; IRS, Insulin receptor substrate; JNK, c-Jun N-terminal kinase; Keap 1, Kelch-like ECH-associating protein 1; L-Arg; L-arginine; LDL, low-density lipoprotein; LOOHs, Lipid hydroperoxides; MAO, monoamine oxidase; MAPK, mitogen-activated protein kinase; MARE, Maf-recognition element; MDA, malondialdehyde; MMP-2, metalloproteinases -2; MT, metallothionein; NAC, N-acetylcysteine; NADPH, nicotinamide dinucleotide phosphate; NF- $\kappa \mathrm{B}$, nuclear factor $\kappa \mathrm{B}$; NO, nitric oxide; NOX, NADPHoxidase; Nrf2, nuclear factor erythroid 2-related factor 2; NT-proBNP, prohormone B-type natriuretic peptide (BNP); 8-OHdG, 8-hydroxy-2deoxyguanosine; 4-ONE, 4-oxononenal; PARP-1, Poly(ADP-ribose) polymerase inhibitors; PPARs, Peroxisome proliferator-activated receptors; Prx, peroxyredoxin; RAAS, reninangiotensin-aldosterone system; Ref-1, redox factor-1; ROS, reactive oxygen species; RNS, reactive nitrogen species; S1P, sphingosine 1-phosphate; SOD, superoxide dismutase; TGF, 
transforming growth factor; Th, T Helper; TNF, tumor necrosis factor; Treg, Regulatory T; TRP, transient receptor potential; Trx, thioredoxin; UCP, Uncoupling protein. 


\section{Conflict of interest}

The authors confirm that this article content has no conflicts of interest.

\section{Acknowledgments}

The authors wish to thank Martine Goiset for secretarial assistance and Philip Bastable for English assistance.

\section{Funding}

This work was supported by grants from the French Ministry of Research, from the Institut National de la Santé et de la Recherche Médicale (INSERM) and from the Regional Council of Burgundy (Conseil Régional de Bourgogne), FEDER and Association de Cardiologie de Bourgogne. 


\section{References}

[1] S. Wild, G. Roglic, A. Green, R. Sicree, H. King, Global prevalence of diabetes: estimates for the year 2000 and projections for 2030, Diabetes Care, 27 (2004) 1047-1053.

[2] T. Mazzone, A. Chait, J. Plutzky, Cardiovascular disease risk in type 2 diabetes mellitus: insights from mechanistic studies, Lancet, 371 (2008) 1800-1809.

[3] M. Zeller, P.G. Steg, J. Ravisy, L. Lorgis, Y. Laurent, P. Sicard, L. Janin-Manificat, J.C. Beer, H. Makki, A.C. Lagrost, L. Rochette, Y. Cottin, Relation between body mass index, waist circumference, and death after acute myocardial infarction, Circulation, 118 (2008) 482-490.

[4] D.T. Graves, R.A. Kayal, Diabetic complications and dysregulated innate immunity, Frontiers in bioscience : a journal and virtual library, 13 (2008) 1227-1239.

[5] R. Paoletti, C. Bolego, A. Poli, A. Cignarella, Metabolic syndrome, inflammation and atherosclerosis, Vascular health and risk management, 2 (2006) 145-152.

[6] C.M. Sena, A.M. Pereira, R. Seica, Endothelial dysfunction - a major mediator of diabetic vascular disease, Biochimica et biophysica acta, 1832 (2013) 2216-2231.

[7] J.S. Dobrin, D. Lebeche, Diabetic cardiomyopathy: signaling defects and therapeutic approaches, Expert review of cardiovascular therapy, 8 (2010) 373-391.

[8] L.H. Opie, D.M. Yellon, B.J. Gersh, Controversies in the cardiovascular management of type 2 diabetes, Heart, 97 (2011) 6-14.

[9] S. Singh, S. Dhingra, D.D. Ramdath, S. Vasdev, V. Gill, P.K. Singal, Risk factors preceding type 2 diabetes and cardiomyopathy, Journal of cardiovascular translational research, 3 (2010) 580-596.

[10] C. Herder, M. Karakas, W. Koenig, Biomarkers for the prediction of type 2 diabetes and cardiovascular disease, Clinical pharmacology and therapeutics, 90 (2011) 52-66.

[11] D.J. Marchant, J.H. Boyd, D.C. Lin, D.J. Granville, F.S. Garmaroudi, B.M. McManus, Inflammation in myocardial diseases, Circ Res, 110 (2012) 126-144.

[12] A. Taube, R. Schlich, H. Sell, K. Eckardt, J. Eckel, Inflammation and metabolic dysfunction: links to cardiovascular diseases, Am J Physiol Heart Circ Physiol, 302 (2012) H2148-2165.

[13] M. Zeller, B. Verges, I. L'Huillier, J.M. Brun, Y. Cottin, Glycemia in acute coronary syndromes, Diabetes \& metabolism, 32 Spec No2 (2006) 2S42-47.

[14] G. Rioufol, M. Zeller, A. Oudot, I. L'Huillier, P. Buffet, J.C. Beer, B. Verges, J.E. Wolf, L. Rochette, Y. Cottin, [Predictive value of glycemia in acute coronary syndromes], Arch Mal Coeur Vaiss (Paris), 97 Spec No 3 (2004) 47-50.

[15] M. Roffi, F.R. Eberli, Diabetes and acute coronary syndromes, Best practice \& research. Clinical endocrinology \& metabolism, 23 (2009) 305-316.

[16] B. Verges, M. Zeller, J. Desgres, G. Dentan, Y. Laurent, L. Janin-Manificat, I. L'Huillier, G. Rioufol, J.C. Beer, H. Makki, L. Rochette, P. Gambert, Y. Cottin, High plasma N-terminal pro-brain natriuretic peptide level found in diabetic patients after myocardial infarction is associated with an increased risk of in-hospital mortality and cardiogenic shock, Eur Heart J, 26 (2005) 1734-1741.

[17] G. Gruden, F. Barutta, N. Chaturvedi, C. Schalkwijk, C.D. Stehouwer, S. Pinach, M. Manzo, M. Loiacono, M. Tricarico, G. Mengozzi, D.R. Witte, J.H. Fuller, P.C. Perin, G. Bruno, NH2-terminal probrain natriuretic peptide is associated with diabetes complications in the EURODIAB Prospective Complications Study: the role of tumor necrosis factor-alpha, Diabetes Care, 35 (2012) 1931-1936.

[18] I. Jialal, S. Devaraj, S.K. Venugopal, Oxidative stress, inflammation, and diabetic vasculopathies: the role of alpha tocopherol therapy, Free Radic Res, 36 (2002) 1331-1336.

[19] S. Lecour, L. Rochette, L. Opie, Free radicals trigger TNF alpha-induced cardioprotection, Cardiovas Res, 65 (2005) 239-243.

[20] S. Lecour, R.M. Smith, B. Woodward, L.H. Opie, L. Rochette, M.N. Sack, Identification of a novel role for sphingolipid signaling in TNF alpha and ischemic preconditioning mediated cardioprotection, J Mol Cell Cardiol, 34 (2002) 509-518. 
[21] A. Cauwels, P. Brouckaert, Survival of TNF toxicity: dependence on caspases and NO, Arch Biochem Biophys, 462 (2007) 132-139.

[22] B. Halliwell, J.M. Gutteridge, The definition and measurement of antioxidants in biological systems, Free Radic Biol Med, 18 (1995) 125-126.

[23] C. Vergely, V. Maupoil, G. Clermont, A. Bril, L. Rochette, Identification and quantification of free radicals during myocardial ischemia and reperfusion using electron paramagnetic resonance spectroscopy, Arch Biochem Biophys, 420 (2003) 209-216.

[24] A.C. Montezano, R.M. Touyz, Reactive oxygen species and endothelial function--role of nitric oxide synthase uncoupling and Nox family nicotinamide adenine dinucleotide phosphate oxidases, Basic \& clinical pharmacology \& toxicology, 110 (2012) 87-94.

[25] A. Oudot, C. Martin, D. Busseuil, C. Vergely, L. Demaison, L. Rochette, NADPH oxidases are in part responsible for increased cardiovascular superoxide production during aging, Free Radic Biol Med, 40 (2006) 2214-2222.

[26] C. Richard, B. Lauzier, S. Delemasure, S. Talbot, S. Ghibu, B. Collin, J. Senecal, F. Menetrier, C. Vergely, R. Couture, L. Rochette, Effects of angiotensin-1 converting enzyme inhibition on oxidative stress and bradykinin receptor expression during doxorubicin-induced cardiomyopathy in rats, J Cardiovasc Pharmacol, 52 (2008) 278-285.

[27] S. Nemoto, T. Finkel, Redox regulation of forkhead proteins through a p66shc-dependent signaling pathway, Science, 295 (2002) 2450-2452.

[28] E. Migliaccio, M. Giorgio, P.G. Pelicci, Apoptosis and aging: role of p66Shc redox protein, Antioxidants \& redox signaling, 8 (2006) 600-608.

[29] K. Su, D. Bourdette, M. Forte, Mitochondrial dysfunction and neurodegeneration in multiple sclerosis, Frontiers in physiology, 4 (2013) 169.

[30] A. Berry, F. Cirulli, The p66(Shc) gene paves the way for healthspan: evolutionary and mechanistic perspectives, Neuroscience and biobehavioral reviews, 37 (2013) 790-802.

[31] P. Pinton, R. Rizzuto, p66Shc, oxidative stress and aging: importing a lifespan determinant into mitochondria, Cell Cycle, 7 (2008) 304-308.

[32] S.C. Ranieri, S. Fusco, E. Panieri, V. Labate, M. Mele, V. Tesori, A.M. Ferrara, G. Maulucci, M. De Spirito, G.E. Martorana, T. Galeotti, G. Pani, Mammalian life-span determinant p66shcA mediates obesity-induced insulin resistance, Proceedings of the National Academy of Sciences of the United States of America, 107 (2010) 13420-13425.

[33] L.L. Dugan, Y.H. You, S.S. Ali, M. Diamond-Stanic, S. Miyamoto, A.E. DeCleves, A. Andreyev, T. Quach, S. Ly, G. Shekhtman, W. Nguyen, A. Chepetan, T.P. Le, L. Wang, M. Xu, K.P. Paik, A. Fogo, B. Viollet, A. Murphy, F. Brosius, R.K. Naviaux, K. Sharma, AMPK dysregulation promotes diabetesrelated reduction of superoxide and mitochondrial function, The Journal of clinical investigation, 123 (2013) 4888-4899.

[34] E. Pagnin, G. Fadini, R. de Toni, A. Tiengo, L. Calo, A. Avogaro, Diabetes induces p66shc gene expression in human peripheral blood mononuclear cells: relationship to oxidative stress, The Journal of clinical endocrinology and metabolism, 90 (2005) 1130-1136.

[35] F. Paneni, P. Mocharla, A. Akhmedov, S. Costantino, E. Osto, M. Volpe, T.F. Luscher, F. Cosentino, Gene silencing of the mitochondrial adaptor p66(Shc) suppresses vascular hyperglycemic memory in diabetes, Circulation research, 111 (2012) 278-289.

[36] S.F. Nunes, I.V. Figueiredo, J.S. Pereira, E.T. de Lemos, F. Reis, F. Teixeira, M.M. Caramona, Monoamine oxidase and semicarbazide-sensitive amine oxidase kinetic analysis in mesenteric arteries of patients with type 2 diabetes, Physiol Res, 60 (2011) 309-315.

[37] Z. Xia, P.M. Vanhoutte, Nitric oxide and protection against cardiac ischemia, Curr Pharm Des, 17 (2011) 1774-1782.

[38] M. Feletou, R. Kohler, P.M. Vanhoutte, Nitric oxide: orchestrator of endothelium-dependent responses, Annals of medicine, 44 (2012) 694-716.

[39] C. Korandji, M. Zeller, J.C. Guilland, C. Vergely, P. Sicard, L. Duvillard, P. Gambert, D. Moreau, Y. Cottin, L. Rochette, Asymmetric dimethylarginine (ADMA) and hyperhomocysteinemia in patients with acute myocardial infarction, Clin Biochem, 40 (2007) 66-72. 
[40] L. Tarnow, P. Hovind, T. Teerlink, C.D. Stehouwer, H.H. Parving, Elevated plasma asymmetric dimethylarginine as a marker of cardiovascular morbidity in early diabetic nephropathy in type 1 diabetes, Diabetes Care, 27 (2004) 765-769.

[41] J.H. Lee, G.H. Park, Y.K. Lee, J.H. Park, Changes in the arginine methylation of organ proteins during the development of diabetes mellitus, Diabetes research and clinical practice, 94 (2011) 111118.

[42] C. Korandji, M. Zeller, J.C. Guilland, B. Collin, B. Lauzier, P. Sicard, L. Duvillard, F. Goirand, D. Moreau, Y. Cottin, L. Rochette, C. Vergely, Time course of asymmetric dimethylarginine (ADMA) and oxidative stress in fructose-hypertensive rats: a model related to metabolic syndrome, Atherosclerosis, 214 (2011) 310-315.

[43] S. Abhary, N. Kasmeridis, K.P. Burdon, A. Kuot, M.J. Whiting, W.P. Yew, N. Petrovsky, J.E. Craig, Diabetic retinopathy is associated with elevated serum asymmetric and symmetric dimethylarginines, Diabetes Care, 32 (2009) 2084-2086.

[44] L. Rochette, C. Vergely, [Hydrogen sulfide (H2S), an endogenous gas with odor of rotten eggs might be a cardiovascular function regulator], Ann Cardiol Angeiol (Paris), 57 (2008) 136-138.

[45] L. Rochette, C. Vergely, Forgotten radicals in biology, International Journal of Biomedical Sciences, 4 (2008) 255-259.

[46] L. Rochette, Y. Cottin, M. Zeller, C. Vergely, Carbon monoxide: mechanisms of action and potential clinical implications, Pharmacol Ther, 137 (2013) 133-152.

[47] L. Rochette, E. Tatou, V. Maupoil, M. Zeller, Y. Cottin, S. Jazayeri, R. Brenot, C. Girard, M. David, C. Vergely, Atrial and vascular oxidative stress in patients with heart failure, Cell Physiol Biochem, 27 (2011) 497-502.

[48] J.Y. Uriu-Adams, C.L. Keen, Copper, oxidative stress, and human health, Molecular aspects of medicine, 26 (2005) 268-298.

[49] B. Ruttkay-Nedecky, L. Nejdl, J. Gumulec, O. Zitka, M. Masarik, T. Eckschlager, M. Stiborova, V. Adam, R. Kizek, The role of metallothionein in oxidative stress, International journal of molecular sciences, 14 (2013) 6044-6066.

[50] H. Tachibana, D. Ogawa, N. Sogawa, M. Asanuma, I. Miyazaki, N. Terami, T. Hatanaka, C.S. Horiguchi, A. Nakatsuka, J. Eguchi, J. Wada, H. Yamada, K. Takei, H. Makino, Metallothionein deficiency exacerbates diabetic nephropathy in streptozotocin-induced diabetic mice, Am J Physiol Renal Physiol, 306 (2014) F105-115.

[51] C. Martin, H. Dubouchaud, L. Mosoni, J.M. Chardigny, A. Oudot, E. Fontaine, C. Vergely, C. Keriel, L. Rochette, X. Leverve, L. Demaison, Abnormalities of mitochondrial functioning can partly explain the metabolic disorders encountered in sarcopenic gastrocnemius, Aging Cell, 6 (2007) 165-177.

[52] D.P. Jones, Redefining oxidative stress, Antioxid Redox Signal, 8 (2006) 1865-1879.

[53] D.P. Jones, Y.M. Go, Redox compartmentalization and cellular stress, Diabetes Obes Metab, 12 Suppl 2 (2010) 116-125.

[54] J.R. Roede, Y.M. Go, D.P. Jones, Redox equivalents and mitochondrial bioenergetics, Methods Mol Biol, 810 (2012) 249-280.

[55] A.J. Chicco, G.C. Sparagna, Role of cardiolipin alterations in mitochondrial dysfunction and disease, American journal of physiology. Cell physiology, 292 (2007) C33-44.

[56] C. Courderot-Masuyer, J.J. Lahet, B. Verges, J.M. Brun, L. Rochette, Ascorbyl free radical release in diabetic patients, Cell Mol Biol (Noisy-le-grand), 46 (2000) 1397-1401.

[57] F. Giacco, M. Brownlee, Oxidative stress and diabetic complications, Circ Res, 107 (2010) 10581070.

[58] J.R. Treberg, M.D. Brand, A model of the proton translocation mechanism of complex I, J Biol Chem, 286 (2011) 17579-17584.

[59] S. Yamagishi, S. Maeda, T. Matsui, S. Ueda, K. Fukami, S. Okuda, Role of advanced glycation end products (AGEs) and oxidative stress in vascular complications in diabetes, Biochimica et biophysica acta, 1820 (2012) 663-671.

[60] X. Wang, L. Tao, C.X. Hai, Redox-regulating role of insulin: the essence of insulin effect, Molecular and cellular endocrinology, 349 (2012) 111-127. 
[61] P. Newsholme, E.P. Haber, S.M. Hirabara, E.L. Rebelato, J. Procopio, D. Morgan, H.C. OliveiraEmilio, A.R. Carpinelli, R. Curi, Diabetes associated cell stress and dysfunction: role of mitochondrial and non-mitochondrial ROS production and activity, J Physiol, 583 (2007) 9-24.

[62] C.Y. Han, T. Umemoto, M. Omer, L.J. Den Hartigh, T. Chiba, R. LeBoeuf, C.L. Buller, I.R. Sweet, S. Pennathur, E.D. Abel, A. Chait, NADPH oxidase-derived reactive oxygen species increases expression of monocyte chemotactic factor genes in cultured adipocytes, J Biol Chem, 287 (2012) 10379-10393.

[63] S.P. Gray, E. Di Marco, J. Okabe, C. Szyndralewiez, F. Heitz, A.C. Montezano, J.B. de Haan, C. Koulis, A. El-Osta, K.L. Andrews, J.P. Chin-Dusting, R.M. Touyz, K. Wingler, M.E. Cooper, H.H. Schmidt, K.A. Jandeleit-Dahm, NADPH oxidase 1 plays a key role in diabetes mellitus-accelerated atherosclerosis, Circulation, 127 (2013) 1888-1902.

[64] P. Storz, Forkhead homeobox type $O$ transcription factors in the responses to oxidative stress, Antioxid Redox Signal, 14 (2011) 593-605.

[65] M. Milkiewicz, E. Roudier, J.L. Doyle, A. Trifonova, O. Birot, T.L. Haas, Identification of a mechanism underlying regulation of the anti-angiogenic forkhead transcription factor FoxO1 in cultured endothelial cells and ischemic muscle, Am J Pathol, 178 (2011) 935-944.

[66] A.V. Nunn, G.W. Guy, J.D. Bell, Endocannabinoids, FOXO and the metabolic syndrome: redox, function and tipping point--the view from two systems, Immunobiology, 215 (2010) 617-628.

[67] D.N. Gross, A.P. van den Heuvel, M.J. Birnbaum, The role of FoxO in the regulation of metabolism, Oncogene, 27 (2008) 2320-2336.

[68] J.H. Lim, H.J. Lee, M. Ho Jung, J. Song, Coupling mitochondrial dysfunction to endoplasmic reticulum stress response: a molecular mechanism leading to hepatic insulin resistance, Cellular signalling, 21 (2009) 169-177.

[69] B.M. Hybertson, B. Gao, S.K. Bose, J.M. McCord, Oxidative stress in health and disease: the therapeutic potential of Nrf2 activation, Molecular aspects of medicine, 32 (2011) 234-246.

[70] M. Kodiha, U. Stochaj, Nuclear transport: a switch for the oxidative stress-signaling circuit?, Journal of signal transduction, 2012 (2012) 208650.

[71] S. Magesh, Y. Chen, L. Hu, Small molecule modulators of Keap1-Nrf2-ARE pathway as potential preventive and therapeutic agents, Medicinal research reviews, 32 (2012) 687-726.

[72] G. Negi, A. Kumar, R.P. Joshi, S.S. Sharma, Oxidative stress and Nrf2 in the pathophysiology of diabetic neuropathy: old perspective with a new angle, Biochem Biophys Res Commun, 408 (2011) 15.

[73] R. Pazdro, J.R. Burgess, The role of vitamin E and oxidative stress in diabetes complications, Mech Ageing Dev, 131 (2010) 276-286.

[74] T.D. Hock, K. Liby, M.M. Wright, S. McConnell, M. Schorpp-Kistner, T.M. Ryan, A. Agarwal, JunB and JunD regulate human heme oxygenase-1 gene expression in renal epithelial cells, J Biol Chem, 282 (2007) 6875-6886.

[75] M. Galli, F. Van Gool, O. Leo, Sirtuins and inflammation: Friends or foes?, Biochem Pharmacol, 81 (2011) 569-576.

[76] H. Sabatel, C. Pirlot, J. Piette, Y. Habraken, Importance of PIKKs in NF-kappaB activation by genotoxic stress, Biochem Pharmacol, 82 (2011) 1371-1383.

[77] C.W. Younce, K. Wang, P.E. Kolattukudy, Hyperglycaemia-induced cardiomyocyte death is mediated via MCP-1 production and induction of a novel zinc-finger protein MCPIP, Cardiovasc Res, 87 (2010) 665-674.

[78] M. Kitamura, Control of NF-kappaB and inflammation by the unfolded protein response, International reviews of immunology, 30 (2011) 4-15.

[79] J.P. Whitehead, Diabetes: New conductors for the peroxisome proliferator-activated receptor gamma (PPARgamma) orchestra, The international journal of biochemistry \& cell biology, 43 (2011) 1071-1074.

[80] A.C. Calkin, M.E. Cooper, K.A. Jandeleit-Dahm, T.J. Allen, Gemfibrozil decreases atherosclerosis in experimental diabetes in association with a reduction in oxidative stress and inflammation, Diabetologia, 49 (2006) 766-774. 
[81] W.T. Wong, X.Y. Tian, A. Xu, J. Yu, C.W. Lau, R.L. Hoo, Y. Wang, V.W. Lee, K.S. Lam, P.M. Vanhoutte, Y. Huang, Adiponectin is required for PPARgamma-mediated improvement of endothelial function in diabetic mice, Cell Metab, 14 (2011) 104-115.

[82] J. Conde, M. Scotece, R. Gomez, V. Lopez, J.J. Gomez-Reino, F. Lago, O. Gualillo, Adipokines: biofactors from white adipose tissue. A complex hub among inflammation, metabolism, and immunity, Biofactors, 37 (2011) 413-420.

[83] J.P. Lu, Z.F. Hou, W.C. Duivenvoorden, K. Whelan, A. Honig, J.H. Pinthus, Adiponectin inhibits oxidative stress in human prostate carcinoma cells, Prostate cancer and prostatic diseases, 15 (2012) 28-35.

[84] M.D. Li, X. Yang, A Retrospective on Nuclear Receptor Regulation of Inflammation: Lessons from GR and PPARs, PPAR research, 2011 (2011) 742785.

[85] Y. Dohi, T. Ikura, Y. Hoshikawa, Y. Katoh, K. Ota, A. Nakanome, A. Muto, S. Omura, T. Ohta, A. Ito, M. Yoshida, T. Noda, K. Igarashi, Bach1 inhibits oxidative stress-induced cellular senescence by impeding p53 function on chromatin, Nature structural \& molecular biology, 15 (2008) 1246-1254.

[86] K. Igarashi, J. Sun, The heme-Bach1 pathway in the regulation of oxidative stress response and erythroid differentiation, Antioxid Redox Signal, 8 (2006) 107-118.

[87] L. Vanella, D.H. Kim, K. Sodhi, I. Barbagallo, A.P. Burgess, J.R. Falck, M.L. Schwartzman, N.G. Abraham, Crosstalk between EET and HO-1 downregulates Bach1 and adipogenic marker expression in mesenchymal stem cell derived adipocytes, Prostaglandins \& other lipid mediators, 96 (2011) 5462.

[88] K.P. Malabanan, L.M. Khachigian, Activation transcription factor-4 and the acute vascular response to injury, J Mol Med (Berl), 88 (2010) 545-552.

[89] N. Goda, M. Kanai, Hypoxia-inducible factors and their roles in energy metabolism, International journal of hematology, 95 (2012) 457-463.

[90] G. Czibik, Complex role of the HIF system in cardiovascular biology, J Mol Med (Berl), 88 (2010) 1101-1111.

[91] C.F. Bento, P. Pereira, Regulation of hypoxia-inducible factor 1 and the loss of the cellular response to hypoxia in diabetes, Diabetologia, 54 (2011) 1946-1956.

[92] W.D. Xu, H.F. Pan, D.Q. Ye, Y. Xu, Targeting IRF4 in autoimmune diseases, Autoimmunity reviews, 11 (2012) 918-924.

[93] D.H. Lovett, R. Mahimkar, R.L. Raffai, L. Cape, E. Maklashina, G. Cecchini, J.S. Karliner, A novel intracellular isoform of matrix metalloproteinase-2 induced by oxidative stress activates innate immunity, PloS one, 7 (2012) e34177.

[94] J.R. Koenitzer, B.A. Freeman, Redox signaling in inflammation: interactions of endogenous electrophiles and mitochondria in cardiovascular disease, Annals of the New York Academy of Sciences, 1203 (2010) 45-52.

[95] G. Poli, R.J. Schaur, W.G. Siems, G. Leonarduzzi, 4-hydroxynonenal: a membrane lipid oxidation product of medicinal interest, Medicinal research reviews, 28 (2008) 569-631.

[96] A.L. Groeger, B.A. Freeman, Signaling actions of electrophiles: anti-inflammatory therapeutic candidates, Molecular interventions, 10 (2010) 39-50.

[97] G. Cohen, Y. Riahi, O. Shamni, M. Guichardant, C. Chatgilialoglu, C. Ferreri, N. Kaiser, S. Sasson, Role of lipid peroxidation and PPAR-delta in amplifying glucose-stimulated insulin secretion, Diabetes, 60 (2011) 2830-2842.

[98] D. Demozay, J.C. Mas, S. Rocchi, E. Van Obberghen, FALDH reverses the deleterious action of oxidative stress induced by lipid peroxidation product 4-hydroxynonenal on insulin signaling in 3T3L1 adipocytes, Diabetes, 57 (2008) 1216-1226.

[99] S. Numazawa, M. Takase, T. Ahiko, M. Ishii, S. Shimizu, T. Yoshida, Possible involvement of transient receptor potential channels in electrophile-induced insulin secretion from RINm5F cells, Biol Pharm Bull, 35 (2012) 346-354.

[100] X. Cheng, R.C. Siow, G.E. Mann, Impaired redox signaling and antioxidant gene expression in endothelial cells in diabetes: a role for mitochondria and the nuclear factor-E2-related factor 2-Kelchlike ECH-associated protein 1 defense pathway, Antioxid Redox Signal, 14 (2011) 469-487. 
[101] T. Sawa, H. Ihara, T. Akaike, Antioxidant effect of a nitrated cyclic nucleotide functioning as an endogenous electrophile, Current topics in medicinal chemistry, 11 (2011) 1854-1860.

[102] T. Hla, A.J. Dannenberg, Sphingolipid signaling in metabolic disorders, Cell Metab, 16 (2012) 420-434.

[103] C. Christoffersen, H. Obinata, S.B. Kumaraswamy, S. Galvani, J. Ahnstrom, M. Sevvana, C. Egerer-Sieber, Y.A. Muller, T. Hla, L.B. Nielsen, B. Dahlback, Endothelium-protective sphingosine-1phosphate provided by HDL-associated apolipoprotein M, Proc Natl Acad Sci U S A, 108 (2011) 96139618.

[104] K. Sattler, B. Levkau, Sphingosine-1-phosphate as a mediator of high-density lipoprotein effects in cardiovascular protection, Cardiovasc Res, 82 (2009) 201-211.

[105] M. Maceyka, K.B. Harikumar, S. Milstien, S. Spiegel, Sphingosine-1-phosphate signaling and its role in disease, Trends in cell biology, 22 (2012) 50-60.

[106] H. Obinata, T. Hla, Sphingosine 1-phosphate in coagulation and inflammation, Seminars in immunopathology, 34 (2012) 73-91.

[107] S.A. Summers, Sphingolipids and insulin resistance: the five Ws, Current opinion in lipidology, 21 (2010) 128-135.

[108] T.E. Fox, M.C. Bewley, K.A. Unrath, M.M. Pedersen, R.E. Anderson, D.Y. Jung, L.S. Jefferson, J.K. Kim, S.K. Bronson, J.M. Flanagan, M. Kester, Circulating sphingolipid biomarkers in models of type 1 diabetes, Journal of lipid research, 52 (2011) 509-517.

[109] W.L. Holland, R.A. Miller, Z.V. Wang, K. Sun, B.M. Barth, H.H. Bui, K.E. Davis, B.T. Bikman, N. Halberg, J.M. Rutkowski, M.R. Wade, V.M. Tenorio, M.S. Kuo, J.T. Brozinick, B.B. Zhang, M.J. Birnbaum, S.A. Summers, P.E. Scherer, Receptor-mediated activation of ceramidase activity initiates the pleiotropic actions of adiponectin, Nat Med, 17 (2011) 55-63.

[110] S. Gorogawa, Y. Kajimoto, Y. Umayahara, H. Kaneto, H. Watada, A. Kuroda, D. Kawamori, T. Yasuda, M. Matsuhisa, Y. Yamasaki, M. Hori, Probucol preserves pancreatic beta-cell function through reduction of oxidative stress in type 2 diabetes, Diabetes research and clinical practice, 57 (2002) 1-10.

[111] Y. Tanaka, P.O. Tran, J. Harmon, R.P. Robertson, A role for glutathione peroxidase in protecting pancreatic beta cells against oxidative stress in a model of glucose toxicity, Proc Natl Acad Sci U S A, 99 (2002) 12363-12368.

[112] H. Kaneto, Y. Kajimoto, J. Miyagawa, T. Matsuoka, Y. Fujitani, Y. Umayahara, T. Hanafusa, Y. Matsuzawa, Y. Yamasaki, M. Hori, Beneficial effects of antioxidants in diabetes: possible protection of pancreatic beta-cells against glucose toxicity, Diabetes, 48 (1999) 2398-2406.

[113] J.L. Evans, I.D. Goldfine, B.A. Maddux, G.M. Grodsky, Are oxidative stress-activated signaling pathways mediators of insulin resistance and beta-cell dysfunction?, Diabetes, 52 (2003) 1-8.

[114] H. Kaneto, G. Xu, N. Fujii, S. Kim, S. Bonner-Weir, G.C. Weir, Involvement of c-Jun N-terminal kinase in oxidative stress-mediated suppression of insulin gene expression, J Biol Chem, 277 (2002) 30010-30018.

[115] H. Kaneto, T.A. Matsuoka, Y. Nakatani, T. Miyatsuka, M. Matsuhisa, M. Hori, Y. Yamasaki, A crucial role of MafA as a novel therapeutic target for diabetes, J Biol Chem, 280 (2005) 15047-15052.

[116] V. Poitout, R.P. Robertson, Minireview: Secondary beta-cell failure in type 2 diabetes--a convergence of glucotoxicity and lipotoxicity, Endocrinology, 143 (2002) 339-342.

[117] K. Maedler, G.A. Spinas, D. Dyntar, W. Moritz, N. Kaiser, M.Y. Donath, Distinct effects of saturated and monounsaturated fatty acids on beta-cell turnover and function, Diabetes, 50 (2001) 69-76.

[118] C. Piperi, C. Adamopoulos, G. Dalagiorgou, E. Diamanti-Kandarakis, A.G. Papavassiliou, Crosstalk between advanced glycation and endoplasmic reticulum stress: emerging therapeutic targeting for metabolic diseases, J Clin Endocrinol Metab, 97 (2012) 2231-2242.

[119] A. Gorlach, P. Klappa, T. Kietzmann, The endoplasmic reticulum: folding, calcium homeostasis, signaling, and redox control, Antioxid Redox Signal, 8 (2006) 1391-1418. 
[120] C. Perrin-Sarrado, O. Bouchot, C. Vergely, L. Rochette, Release of secondary free radicals during post-ischaemic reperfusion is not influenced by extracellular calcium levels in isolated rat hearts, Mol Cell Biochem, 297 (2007) 199-207.

[121] R.P. Robertson, H. Zhou, M. Slucca, A role for zinc in pancreatic islet beta-cell cross-talk with the alpha-cell during hypoglycaemia, Diabetes Obes Metab, 13 Suppl 1 (2011) 106-111.

[122] B. Colsoul, R. Vennekens, B. Nilius, Transient receptor potential cation channels in pancreatic beta cells, Reviews of physiology, biochemistry and pharmacology, 161 (2011) 87-110.

[123] M.S. Jamaluddin, S.M. Weakley, Q. Yao, C. Chen, Resistin: functional roles and therapeutic considerations for cardiovascular disease, Br J Pharmacol, 165 (2012) 622-632.

[124] P.M. Perez, R. Moore-Carrasco, D.R. Gonzalez, E.Q. Fuentes, I.G. Palomo, Gene expression of adipose tissue, endothelial cells and platelets in subjects with metabolic syndrome (Review), Molecular medicine reports, 5 (2012) 1135-1140.

[125] P. Wang, E. Mariman, J. Renes, J. Keijer, The secretory function of adipocytes in the physiology of white adipose tissue, Journal of cellular physiology, 216 (2008) 3-13.

[126] N.S. Kalupahana, N. Moustaid-Moussa, K.J. Claycombe, Immunity as a link between obesity and insulin resistance, Molecular aspects of medicine, 33 (2012) 26-34.

[127] S.C. Ranieri, S. Fusco, G. Pani, p66(ShcA): linking mammalian longevity with obesity-induced insulin resistance, Vitamins and hormones, 91 (2013) 219-241.

[128] J.L. Evans, I.D. Goldfine, B.A. Maddux, G.M. Grodsky, Oxidative stress and stress-activated signaling pathways: a unifying hypothesis of type 2 diabetes, Endocrine reviews, 23 (2002) 599-622.

[129] J.L. Evans, B.A. Maddux, I.D. Goldfine, The molecular basis for oxidative stress-induced insulin resistance, Antioxid Redox Signal, 7 (2005) 1040-1052.

[130] A.F. Soares, M. Guichardant, D. Cozzone, N. Bernoud-Hubac, N. Bouzaidi-Tiali, M. Lagarde, A. Geloen, Effects of oxidative stress on adiponectin secretion and lactate production in 3T3-L1 adipocytes, Free Radic Biol Med, 38 (2005) 882-889.

[131] L. Tao, E. Gao, X. Jiao, Y. Yuan, S. Li, T.A. Christopher, B.L. Lopez, W. Koch, L. Chan, B.J. Goldstein, X.L. Ma, Adiponectin cardioprotection after myocardial ischemia/reperfusion involves the reduction of oxidative/nitrative stress, Circulation, 115 (2007) 1408-1416.

[132] P.W. Peake, Y. Shen, A. Walther, J.A. Charlesworth, Adiponectin binds C1q and activates the classical pathway of complement, Biochem Biophys Res Commun, 367 (2008) 560-565.

[133] A. Nguyen Dinh Cat, R.M. Touyz, A new look at the renin-angiotensin system--focusing on the vascular system, Peptides, 32 (2011) 2141-2150.

[134] M. Stumvoll, B.J. Goldstein, T.W. van Haeften, Type 2 diabetes: principles of pathogenesis and therapy, Lancet, 365 (2005) 1333-1346.

[135] X. Li, K.A. Becker, Y. Zhang, Ceramide in redox signaling and cardiovascular diseases, Cell Physiol Biochem, 26 (2010) 41-48.

[136] S.A. Summers, Ceramides in insulin resistance and lipotoxicity, Progress in lipid research, 45 (2006) 42-72.

[137] S. Lecour, E. Van der Merwe, L.H. Opie, M.N. Sack, Ceramide attenuates hypoxic cell death via reactive oxygen species signaling, J Cardiovasc Pharmacol, 47 (2006) 158-163.

[138] J.A. Chavez, S.A. Summers, A ceramide-centric view of insulin resistance, Cell Metab, 15 (2012) 585-594.

[139] B.T. Bikman, S.A. Summers, Ceramides as modulators of cellular and whole-body metabolism, J Clin Invest, 121 (2011) 4222-4230.

[140] P. Gao, Y.K. Peterson, R.A. Smith, C.D. Smith, Characterization of isoenzyme-selective inhibitors of human sphingosine kinases, PloS one, 7 (2012) e44543.

[141] H. Kaneto, N. Katakami, D. Kawamori, T. Miyatsuka, K. Sakamoto, T.A. Matsuoka, M. Matsuhisa, Y. Yamasaki, Involvement of oxidative stress in the pathogenesis of diabetes, Antioxid Redox Signal, 9 (2007) 355-366.

[142] H. Otani, Oxidative stress as pathogenesis of cardiovascular risk associated with metabolic syndrome, Antioxid Redox Signal, 15 (2011) 1911-1926. 
[143] I. Batinic-Haberle, J.S. Reboucas, I. Spasojevic, Superoxide dismutase mimics: chemistry, pharmacology, and therapeutic potential, Antioxid Redox Signal, 13 (2010) 877-918.

[144] B.J. Day, Catalase and glutathione peroxidase mimics, Biochem Pharmacol, 77 (2009) 285-296.

[145] T. Munzel, C. Sinning, F. Post, A. Warnholtz, E. Schulz, Pathophysiology, diagnosis and prognostic implications of endothelial dysfunction, Annals of medicine, 40 (2008) 180-196.

[146] A.S. De Vriese, T.J. Verbeuren, J. Van de Voorde, N.H. Lameire, P.M. Vanhoutte, Endothelial dysfunction in diabetes, Br J Pharmacol, 130 (2000) 963-974.

[147] Y. Shi, P.M. Vanhoutte, Reactive oxygen-derived free radicals are key to the endothelial dysfunction of diabetes, Journal of diabetes, 1 (2009) 151-162.

[148] S. Miriyala, I. Spasojevic, A. Tovmasyan, D. Salvemini, Z. Vujaskovic, D. St Clair, I. BatinicHaberle, Manganese superoxide dismutase, MnSOD and its mimics, Biochim Biophys Acta, 1822 (2012) 794-814.

[149] I. Batinic-Haberle, Z. Rajic, A. Tovmasyan, J.S. Reboucas, X. Ye, K.W. Leong, M.W. Dewhirst, Z. Vujaskovic, L. Benov, I. Spasojevic, Diverse functions of cationic $\mathrm{Mn}$ (III) N-substituted pyridylporphyrins, recognized as SOD mimics, Free Radic Biol Med, 51 (2011) 1035-1053.

[150] J.D. Piganelli, S.C. Flores, C. Cruz, J. Koepp, I. Batinic-Haberle, J. Crapo, B. Day, R. Kachadourian, R. Young, B. Bradley, K. Haskins, A metalloporphyrin-based superoxide dismutase mimic inhibits adoptive transfer of autoimmune diabetes by a diabetogenic T-cell clone, Diabetes, 51 (2002) 347355.

[151] M. Rocha, N. Apostolova, J.R. Herance, S. Rovira-Llopis, A. Hernandez-Mijares, V.M. Victor, Perspectives and Potential Applications of Mitochondria-Targeted Antioxidants in Cardiometabolic Diseases and Type 2 Diabetes, Medicinal research reviews, (2013).

[152] A.M. James, H.M. Cocheme, R.A. Smith, M.P. Murphy, Interactions of mitochondria-targeted and untargeted ubiquinones with the mitochondrial respiratory chain and reactive oxygen species. Implications for the use of exogenous ubiquinones as therapies and experimental tools, J Biol Chem, 280 (2005) 21295-21312.

[153] D. Graham, N.N. Huynh, C.A. Hamilton, E. Beattie, R.A. Smith, H.M. Cocheme, M.P. Murphy, A.F. Dominiczak, Mitochondria-targeted antioxidant MitoQ10 improves endothelial function and attenuates cardiac hypertrophy, Hypertension, 54 (2009) 322-328.

[154] J.B. de Haan, M.E. Cooper, Targeted antioxidant therapies in hyperglycemia-mediated endothelial dysfunction, Front Biosci (Schol Ed), 3 (2011) 709-729.

[155] C. Sanmartin, D. Plano, M. Font, J.A. Palop, Selenium and clinical trials: new therapeutic evidence for multiple diseases, Current medicinal chemistry, 18 (2011) 4635-4650.

[156] M. Khullar, A.A. Al-Shudiefat, A. Ludke, G. Binepal, P.K. Singal, Oxidative stress: a key contributor to diabetic cardiomyopathy, Canadian journal of physiology and pharmacology, 88 (2010) 233-240.

[157] M. Ayaz, S. Ozdemir, M. Ugur, G. Vassort, B. Turan, Effects of selenium on altered mechanical and electrical cardiac activities of diabetic rat, Arch Biochem Biophys, 426 (2004) 83-90.

[158] M.G. Traber, J.F. Stevens, Vitamins C and E: beneficial effects from a mechanistic perspective, Free Radic Biol Med, 51 (2011) 1000-1013.

[159] J.J. Lahet, C. Courderot-Masuyer, F. Lenfant, E. Tatou, C. Vergely, M. David, L. Rochette, The influence of extracorporeal circulation on the susceptibility of erythrocytes to oxidative stress, Free Radic Res, 38 (2004) 683-689.

[160] C. Vergely, V. Maupoil, M. Benderitter, L. Rochette, Influence of the severity of myocardial ischemia on the intensity of ascorbyl free radical release and on post-ischemic recovery during reperfusion, Free Radic Biol Med, 24 (1998) 470-479.

[161] B. Garcia-Bailo, A. El-Sohemy, P.S. Haddad, P. Arora, F. Benzaied, M. Karmali, A. Badawi, Vitamins $D, C$, and $E$ in the prevention of type 2 diabetes mellitus: modulation of inflammation and oxidative stress, Biologics : targets \& therapy, 5 (2011) 7-19.

[162] G. Clermont, S. Lecour, J.F. Cabanne, G. Motte, J.C. Guilland, D. Chevet, L. Rochette, Vitamin Ecoated dialyzer reduces oxidative stress in hemodialysis patients, Free Radic Biol Med, 31 (2001) 233241. 
[163] R.Z. Fardoun, The use of vitamin E in type 2 diabetes mellitus, Clin Exp Hypertens, 29 (2007) 135-148.

[164] J.S. Johansen, A.K. Harris, D.J. Rychly, A. Ergul, Oxidative stress and the use of antioxidants in diabetes: linking basic science to clinical practice, Cardiovascular diabetology, 4 (2005) 5.

[165] T. Gori, T. Munzel, Oxidative stress and endothelial dysfunction: therapeutic implications, Annals of medicine, 43 (2011) 259-272.

[166] E.R. Miller, 3rd, R. Pastor-Barriuso, D. Dalal, R.A. Riemersma, L.J. Appel, E. Guallar, Metaanalysis: high-dosage vitamin $E$ supplementation may increase all-cause mortality, Annals of internal medicine, 142 (2005) 37-46.

[167] D. Steinberg, J.L. Witztum, Is the oxidative modification hypothesis relevant to human atherosclerosis? Do the antioxidant trials conducted to date refute the hypothesis?, Circulation, 105 (2002) 2107-2111.

[168] D.P. Vivekananthan, M.S. Penn, S.K. Sapp, A. Hsu, E.J. Topol, Use of antioxidant vitamins for the prevention of cardiovascular disease: meta-analysis of randomised trials, Lancet, 361 (2003) 20172023.

[169] B.G. Brown, J. Crowley, Is there any hope for vitamin E?, Jama, 293 (2005) 1387-1390.

[170] A.S. Kelly, A.M. Thelen, D.R. Kaiser, J.M. Gonzalez-Campoy, A.J. Bank, Rosiglitazone improves endothelial function and inflammation but not asymmetric dimethylarginine or oxidative stress in patients with type 2 diabetes mellitus, Vasc Med, 12 (2007) 311-318.

[171] S. Golbidi, I. Laher, Antioxidant therapy in human endocrine disorders, Medical science monitor : international medical journal of experimental and clinical research, 16 (2010) RA9-24.

[172] S. Blum, M. Vardi, J.B. Brown, A. Russell, U. Milman, C. Shapira, N.S. Levy, R. Miller-Lotan, R. Asleh, A.P. Levy, Vitamin E reduces cardiovascular disease in individuals with diabetes mellitus and the haptoglobin 2-2 genotype, Pharmacogenomics, 11 (2010) 675-684.

[173] B.P. Gargari, V. Aghamohammadi, A. Aliasgharzadeh, Effect of folic acid supplementation on biochemical indices in overweight and obese men with type 2 diabetes, Diabetes research and clinical practice, 94 (2011) 33-38.

[174] Y.H. Zhou, J.Y. Tang, M.J. Wu, J. Lu, X. Wei, Y.Y. Qin, C. Wang, J.F. Xu, J. He, Effect of folic acid supplementation on cardiovascular outcomes: a systematic review and meta-analysis, PloS one, 6 (2011) e25142.

[175] M. Sagara, J. Satoh, R. Wada, S. Yagihashi, K. Takahashi, M. Fukuzawa, G. Muto, Y. Muto, T. Toyota, Inhibition of development of peripheral neuropathy in streptozotocin-induced diabetic rats with N-acetylcysteine, Diabetologia, 39 (1996) 263-269.

[176] A. Love, M.A. Cotter, N.E. Cameron, Effects of the sulphydryl donor N-acetyl-L-cysteine on nerve conduction, perfusion, maturation and regeneration following freeze damage in diabetic rats, European journal of clinical investigation, 26 (1996) 698-706.

[177] K.A. Head, Peripheral neuropathy: pathogenic mechanisms and alternative therapies, Alternative medicine review : a journal of clinical therapeutic, 11 (2006) 294-329.

[178] K.R. Gibson, T.J. Winterburn, F. Barrett, S. Sharma, S.M. MacRury, I.L. Megson, Therapeutic potential of $\mathrm{N}$-acetylcysteine as an antiplatelet agent in patients with type-2 diabetes, Cardiovascular diabetology, 10 (2011) 43.

[179] L. Packer, E.H. Witt, H.J. Tritschler, alpha-Lipoic acid as a biological antioxidant, Free Radic Biol Med, 19 (1995) 227-250.

[180] S. Ghibu, B. Lauzier, S. Delemasure, S. Amoureux, P. Sicard, C. Vergely, A. Muresan, C. Mogosan, L. Rochette, Antioxidant properties of alpha-lipoic acid: effects on red blood membrane permeability and adaptation of isolated rat heart to reversible ischemia, Mol Cell Biochem, 320 (2009) 141-148.

[181] T. Heitzer, B. Finckh, S. Albers, K. Krohn, A. Kohlschutter, T. Meinertz, Beneficial effects of alpha-lipoic acid and ascorbic acid on endothelium-dependent, nitric oxide-mediated vasodilation in diabetic patients: relation to parameters of oxidative stress, Free Radic Biol Med, 31 (2001) 53-61.

[182] K.P. Shay, R.F. Moreau, E.J. Smith, A.R. Smith, T.M. Hagen, Alpha-lipoic acid as a dietary supplement: molecular mechanisms and therapeutic potential, Biochim Biophys Acta, 1790 (2009) 1149-1160. 
[183] D. Ziegler, P.A. Low, W.J. Litchy, A.J. Boulton, A.I. Vinik, R. Freeman, R. Samigullin, H. Tritschler, U. Munzel, J. Maus, K. Schutte, P.J. Dyck, Efficacy and safety of antioxidant treatment with alphalipoic acid over 4 years in diabetic polyneuropathy: the NATHAN 1 trial, Diabetes Care, 34 (2011) 2054-2060.

[184] S.J. Hamilton, G.T. Chew, G.F. Watts, Coenzyme Q10 improves endothelial dysfunction in statintreated type 2 diabetic patients, Diabetes Care, 32 (2009) 810-812.

[185] J.M. Villalba, C. Parrado, M. Santos-Gonzalez, F.J. Alcain, Therapeutic use of coenzyme Q10 and coenzyme Q10-related compounds and formulations, Expert opinion on investigational drugs, 19 (2010) 535-554.

[186] M. Rocha, N. Apostolova, J.R. Herance, S. Rovira-Llopis, A. Hernandez-Mijares, V.M. Victor, Perspectives and potential applications of mitochondria-targeted antioxidants in cardiometabolic diseases and type 2 diabetes, Medicinal research reviews, 34 (2014) 160-189.

[187] M.P. Fink, C.A. Macias, J. Xiao, Y.Y. Tyurina, R.L. Delude, J.S. Greenberger, V.E. Kagan, P. Wipf, Hemigramicidin-TEMPO conjugates: novel mitochondria-targeted antioxidants, Critical care medicine, 35 (2007) S461-467.

[188] J. Huang, X. Li, M. Li, J. Li, W. Xiao, W. Ma, X. Chen, X. Liang, S. Tang, Y. Luo, Mitochondriatargeted antioxidant peptide SS31 protects the retinas of diabetic rats, Curr Mol Med, 13 (2013) 935945.

[189] Q. Liu, L. Sun, Y. Tan, G. Wang, X. Lin, L. Cai, Role of iron deficiency and overload in the pathogenesis of diabetes and diabetic complications, Current medicinal chemistry, 16 (2009) 113129.

[190] S. Swaminathan, V.A. Fonseca, M.G. Alam, S.V. Shah, The role of iron in diabetes and its complications, Diabetes Care, 30 (2007) 1926-1933.

[191] K. Jomova, M. Valko, Advances in metal-induced oxidative stress and human disease, Toxicology, 283 (2011) 65-87.

[192] H. Kim, R.C. Koehler, P.D. Hurn, E.D. Hall, R.J. Traystman, Amelioration of impaired cerebral metabolism after severe acidotic ischemia by tirilazad posttreatment in dogs, Stroke; a journal of cerebral circulation, 27 (1996) 114-121.

[193] N. Yamashita, S. Hoshida, K. Otsu, M. Asahi, T. Kuzuya, M. Hori, Exercise provides direct biphasic cardioprotection via manganese superoxide dismutase activation, J Exp Med, 189 (1999) 1699-1706.

[194] E. Teixeira-Lemos, S. Nunes, F. Teixeira, F. Reis, Regular physical exercise training assists in preventing type 2 diabetes development: focus on its antioxidant and anti-inflammatory properties, Cardiovascular diabetology, 10 (2011) 12.

[195] X. Hou, J. Song, X.N. Li, L. Zhang, X. Wang, L. Chen, Y.H. Shen, Metformin reduces intracellular reactive oxygen species levels by upregulating expression of the antioxidant thioredoxin via the AMPK-FOXO3 pathway, Biochem Biophys Res Commun, 396 (2010) 199-205.

[196] O.O. Erejuwa, S.A. Sulaiman, M.S. Wahab, S.K. Salam, M.S. Salleh, S. Gurtu, Comparison of antioxidant effects of honey, glibenclamide, metformin, and their combinations in the kidneys of streptozotocin-induced diabetic rats, International journal of molecular sciences, 12 (2011) 829-843.

[197] M.C. Asensio-Lopez, A. Lax, D.A. Pascual-Figal, M. Valdes, J. Sanchez-Mas, Metformin protects against doxorubicin-induced cardiotoxicity: involvement of the adiponectin cardiac system, Free Radic Biol Med, 51 (2011) 1861-1871.

[198] H. Kawai, H. Nakai, M. Suga, S. Yuki, T. Watanabe, K.I. Saito, Effects of a novel free radical scavenger, $\mathrm{MCl}-186$, on ischemic brain damage in the rat distal middle cerebral artery occlusion model, J Pharmacol Exp Ther, 281 (1997) 921-927.

[199] K. Satoh, Y. Ikeda, S. Shioda, T. Tobe, T. Yoshikawa, Edarabone scavenges nitric oxide, Redox Rep, 7 (2002) 219-222.

[200] D. Fukudome, M. Matsuda, T. Kawasaki, Y. Ago, T. Matsuda, The radical scavenger edaravone counteracts diabetes in multiple low-dose streptozotocin-treated mice, Eur J Pharmacol, 583 (2008) 164-169. 
[201] U. Schmid, H. Stopper, A. Heidland, N. Schupp, Benfotiamine exhibits direct antioxidative capacity and prevents induction of DNA damage in vitro, Diabetes/metabolism research and reviews, 24 (2008) 371-377.

[202] X. Du, D. Edelstein, M. Brownlee, Oral benfotiamine plus alpha-lipoic acid normalises complication-causing pathways in type 1 diabetes, Diabetologia, 51 (2008) 1930-1932.

[203] N. Rabbani, S.S. Alam, S. Riaz, J.R. Larkin, M.W. Akhtar, T. Shafi, P.J. Thornalley, High-dose thiamine therapy for patients with type 2 diabetes and microalbuminuria: a randomised, doubleblind placebo-controlled pilot study, Diabetologia, 52 (2009) 208-212.

[204] R.K. Sodhi, N. Singh, A.S. Jaggi, Poly(ADP-ribose) polymerase-1 (PARP-1) and its therapeutic implications, Vascul Pharmacol, 53 (2010) 77-87.

[205] P. Pacher, C. Szabo, Role of the peroxynitrite-poly(ADP-ribose) polymerase pathway in human disease, Am J Pathol, 173 (2008) 2-13.

[206] B. Heller, Z.Q. Wang, E.F. Wagner, J. Radons, A. Burkle, K. Fehsel, V. Burkart, H. Kolb, Inactivation of the poly(ADP-ribose) polymerase gene affects oxygen radical and nitric oxide toxicity in islet cells, J Biol Chem, 270 (1995) 11176-11180.

[207] C. Szabo, L. Virag, S. Cuzzocrea, G.S. Scott, P. Hake, M.P. O'Connor, B. Zingarelli, A. Salzman, E. Kun, Protection against peroxynitrite-induced fibroblast injury and arthritis development by inhibition of poly(ADP-ribose) synthase, Proc Natl Acad Sci U S A, 95 (1998) 3867-3872.

[208] V.R. Drel, P. Pacher, R. Stavniichuk, W. Xu, J. Zhang, T.M. Kuchmerovska, B. Slusher, I.G. Obrosova, Poly(ADP-ribose)polymerase inhibition counteracts renal hypertrophy and multiple manifestations of peripheral neuropathy in diabetic Akita mice, International journal of molecular medicine, 28 (2011) 629-635.

[209] H.S. Smith, C.E. Argoff, Pharmacological treatment of diabetic neuropathic pain, Drugs, 71 (2011) 557-589.

[210] W.J. Li, M.K. Shin, S.J. Oh, Poly(ADP-ribose) polymerase is involved in the development of diabetic cystopathy via regulation of nuclear factor kappa B, Urology, 77 (2011) 1265 e1261-1268.

[211] S. Yamagishi, T. Matsui, Nitric oxide, a janus-faced therapeutic target for diabetic microangiopathy-Friend or foe?, Pharmacol Res, 64 (2011) 187-194.

[212] B. Lauzier, P. Sicard, O. Bouchot, S. Delemasure, D. Moreau, C. Vergely, L. Rochette, A peroxynitrite decomposition catalyst: FeTPPS confers cardioprotection during reperfusion after cardioplegic arrest in a working isolated rat heart model, Fundam Clin Pharmacol, 21 (2007) 173-180. [213] G. Ferrer-Sueta, D. Vitturi, I. Batinic-Haberle, I. Fridovich, S. Goldstein, G. Czapski, R. Radi, Reactions of manganese porphyrins with peroxynitrite and carbonate radical anion, J Biol Chem, 278 (2003) 27432-27438.

[214] T.K. Ali, S. Matragoon, B.A. Pillai, G.I. Liou, A.B. El-Remessy, Peroxynitrite mediates retinal neurodegeneration by inhibiting nerve growth factor survival signaling in experimental and human diabetes, Diabetes, 57 (2008) 889-898.

[215] I.G. Obrosova, V.R. Drel, C.L. Oltman, N. Mashtalir, J. Tibrewala, J.T. Groves, M.A. Yorek, Role of nitrosative stress in early neuropathy and vascular dysfunction in streptozotocin-diabetic rats, Am J Physiol Endocrinol Metab, 293 (2007) E1645-1655.

[216] P. Sicard, N. Acar, S. Gregoire, B. Lauzier, A.M. Bron, C. Creuzot-Garcher, L. Bretillon, C. Vergely, L. Rochette, Influence of rosuvastatin on the $\mathrm{NAD}(\mathrm{P}) \mathrm{H}$ oxidase activity in the retina and electroretinographic response of spontaneously hypertensive rats, $\mathrm{Br} J$ Pharmacol, 151 (2007) 979986.

[217] P. Sicard, S. Delemasure, C. Korandji, A. Segueira-Le Grand, B. Lauzier, J.C. Guilland, L. Duvillard, M. Zeller, Y. Cottin, C. Vergely, L. Rochette, Anti-hypertensive effects of Rosuvastatin are associated with decreased inflammation and oxidative stress markers in hypertensive rats, Free Radic Res, 42 (2008) 226-236.

[218] S. Bellosta, N. Ferri, L. Arnaboldi, F. Bernini, R. Paoletti, A. Corsini, Pleiotropic effects of statins in atherosclerosis and diabetes, Diabetes Care, 23 Suppl 2 (2000) B72-78.

[219] T. Munzel, T. Gori, R.M. Bruno, S. Taddei, Is oxidative stress a therapeutic target in cardiovascular disease?, Eur Heart J, 31 (2010) 2741-2748. 
[220] J.M. Luther, N.J. Brown, The renin-angiotensin-aldosterone system and glucose homeostasis, Trends in pharmacological sciences, 32 (2011) 734-739.

[221] A. Oudot, C. Vergely, A. Ecarnot-Laubriet, L. Rochette, Pharmacological concentration of angiotensin-(1-7) activates NADPH oxidase after ischemia-reperfusion in rat heart through AT1 receptor stimulation, Regul Pept, 127 (2005) 101-110.

[222] L.A. Rabelo, N. Alenina, M. Bader, ACE2-angiotensin-(1-7)-Mas axis and oxidative stress in cardiovascular disease, Hypertension research : official journal of the Japanese Society of Hypertension, 34 (2011) 154-160.

[223] P.G. Shekelle, M.W. Rich, S.C. Morton, C.S. Atkinson, W. Tu, M. Maglione, S. Rhodes, M. Barrett, G.C. Fonarow, B. Greenberg, P.A. Heidenreich, T. Knabel, M.A. Konstam, A. Steimle, L. Warner Stevenson, Efficacy of angiotensin-converting enzyme inhibitors and beta-blockers in the management of left ventricular systolic dysfunction according to race, gender, and diabetic status: a meta-analysis of major clinical trials, J Am Coll Cardiol, 41 (2003) 1529-1538.

[224] A.L. Swislocki, D. Siegel, I. Jialal, Pharmacotherapy for the metabolic syndrome, Current vascular pharmacology, 10 (2012) 187-205.

[225] R.I. Meijer, E.H. Serne, Y.M. Smulders, V.W. van Hinsbergh, J.S. Yudkin, E.C. Eringa, Perivascular adipose tissue and its role in type 2 diabetes and cardiovascular disease, Current diabetes reports, 11 (2011) 211-217.

[226] B. Vural, F. Atalar, C. Ciftci, A. Demirkan, B. Susleyici-Duman, D. Gunay, B. Akpinar, E. Sagbas, U. Ozbek, A.S. Buyukdevrim, Presence of fatty-acid-binding protein 4 expression in human epicardial adipose tissue in metabolic syndrome, Cardiovasc Pathol, 17 (2008) 392-398.

[227] M. Heald, M.A. Cawthorne, Dual acting and pan-PPAR activators as potential anti-diabetic therapies, Handbook of experimental pharmacology, (2011) 35-51.

[228] C. Marchesi, E.L. Schiffrin, Peroxisome proliferator-activated receptors and the vascular system: beyond their metabolic effects, Journal of the American Society of Hypertension : JASH, 2 (2008) 227238.

[229] R.M. Touyz, E.L. Schiffrin, Peroxisome proliferator-activated receptors in vascular biologymolecular mechanisms and clinical implications, Vascul Pharmacol, 45 (2006) 19-28.

[230] A. Vinik, H. Parson, J. Ullal, The role of PPARs in the microvascular dysfunction in diabetes, Vascul Pharmacol, 45 (2006) 54-64.

[231] R.B. Clark, The role of PPARs in inflammation and immunity, Journal of leukocyte biology, 71 (2002) 388-400.

[232] S.S. Chung, M. Kim, J.S. Lee, B.Y. Ahn, H.S. Jung, H.M. Lee, K.S. Park, Mechanism for antioxidative effects of thiazolidinediones in pancreatic beta-cells, Am J Physiol Endocrinol Metab, 301 (2011) E912-921.

[233] J.F. Landrier, E. Gouranton, C. El Yazidi, C. Malezet, P. Balaguer, P. Borel, M.J. Amiot, Adiponectin expression is induced by vitamin $\mathrm{E}$ via a peroxisome proliferator-activated receptor gamma-dependent mechanism, Endocrinology, 150 (2009) 5318-5325.

[234] B. Gray, J. Swick, A.G. Ronnenberg, Vitamin E and adiponectin: proposed mechanism for vitamin E-induced improvement in insulin sensitivity, Nutrition reviews, 69 (2011) 155-161.

[235] N. Satoh, Y. Ogawa, T. Usui, T. Tagami, S. Kono, H. Uesugi, H. Sugiyama, A. Sugawara, K. Yamada, A. Shimatsu, H. Kuzuya, K. Nakao, Antiatherogenic effect of pioglitazone in type 2 diabetic patients irrespective of the responsiveness to its antidiabetic effect, Diabetes Care, 26 (2003) 24932499.

[236] T. Hasegawa, K. Okada, Y. Okita, D.J. Pinsky, Antioxidant properties of pioglitazone limit nicotinamide adenine dinucleotide phosphate hydrogen oxidase and augment superoxide dismutase activity in cardiac allotransplantation, J Heart Lung Transplant, 30 (2011) 1186-1196.

[237] R. Simo, C. Hernandez, Advances in the medical treatment of diabetic retinopathy, Diabetes Care, 32 (2009) 1556-1562.

[238] G. Rajaraman, G.Q. Wang, J. Yan, P. Jiang, Y. Gong, F.J. Burczynski, Role of cytosolic liver fatty acid binding protein in hepatocellular oxidative stress: effect of dexamethasone and clofibrate treatment, Mol Cell Biochem, 295 (2007) 27-34. 
[239] E. Krusinova, T. Pelikanova, Fatty acid binding proteins in adipose tissue: a promising link between metabolic syndrome and atherosclerosis?, Diabetes research and clinical practice, 82 Suppl 2 (2008) S127-134.

[240] G.L. Blackburn, From bench to bedside: novel mechanisms and therapeutic advances through the development of selective peroxisome proliferator-activated receptor gamma modulators, Am J Clin Nutr, 91 (2010) 251S-253S.

[241] S. Kralisch, M. Fasshauer, Fibroblast growth factor 21: effects on carbohydrate and lipid metabolism in health and disease, Current opinion in clinical nutrition and metabolic care, 14 (2011) 354-359.

[242] Y. Xiao, A. Xu, L.S. Law, C. Chen, H. Li, X. Li, L. Yang, S. Liu, Z. Zhou, K.S. Lam, Distinct changes in serum fibroblast growth factor 21 levels in different subtypes of diabetes, J Clin Endocrinol Metab, 97 (2012) E54-58.

[243] M.D. Chau, J. Gao, Q. Yang, Z. Wu, J. Gromada, Fibroblast growth factor 21 regulates energy metabolism by activating the AMPK-SIRT1-PGC-1alpha pathway, Proc Natl Acad Sci U S A, 107 (2010) $12553-12558$

[244] R.G. Damazio, A.P. Zanatta, L.H. Cazarolli, A. Mascarello, L.D. Chiaradia, R.J. Nunes, R.A. Yunes, F.R. Silva, Nitrochalcones: potential in vivo insulin secretagogues, Biochimie, 91 (2009) 1493-1498.

[245] R. Kamei, M. Kadokura, Y. Kitagawa, O. Hazeki, S. Oikawa, 2'-benzyloxychalcone derivatives stimulate glucose uptake in 3T3-L1 adipocytes, Life Sci, 73 (2003) 2091-2099.

[246] H.S. Ban, K. Suzuki, S.S. Lim, S.H. Jung, S. Lee, J. Ji, H.S. Lee, Y.S. Lee, K.H. Shin, K. Ohuchi, Inhibition of lipopolysaccharide-induced expression of inducible nitric oxide synthase and tumor necrosis factor-alpha by 2'-hydroxychalcone derivatives in RAW 264.7 cells, Biochem Pharmacol, 67 (2004) 1549-1557.

[247] P. Sawle, B.E. Moulton, M. Jarzykowska, C.J. Green, R. Foresti, I.J. Fairlamb, R. Motterlini, Structure-activity relationships of methoxychalcones as inducers of heme oxygenase-1, Chem Res Toxicol, 21 (2008) 1484-1494.

[248] S.S. Kim, J. Lim, Y. Bang, J. Gal, S.U. Lee, Y.C. Cho, G. Yoon, B.Y. Kang, S.H. Cheon, H.J. Choi, Licochalcone $\mathrm{E}$ activates Nrf2/antioxidant response element signaling pathway in both neuronal and microglial cells: therapeutic relevance to neurodegenerative disease, J Nutr Biochem, 23 (2012) 1314-1323.

[249] H.C. Shen, B.D. Hammock, Discovery of inhibitors of soluble epoxide hydrolase: a target with multiple potential therapeutic indications, Journal of medicinal chemistry, 55 (2012) 1789-1808.

[250] A. Luria, A. Bettaieb, Y. Xi, G.J. Shieh, H.C. Liu, H. Inoue, H.J. Tsai, J.D. Imig, F.G. Haj, B.D. Hammock, Soluble epoxide hydrolase deficiency alters pancreatic islet size and improves glucose homeostasis in a model of insulin resistance, Proc Natl Acad Sci U S A, 108 (2011) 9038-9043.

[251] J.J. Holst, The physiology of glucagon-like peptide 1, Physiol Rev, 87 (2007) 1409-1439.

[252] T. Vilsboll, T. Krarup, J. Sonne, S. Madsbad, A. Volund, A.G. Juul, J.J. Holst, Incretin secretion in relation to meal size and body weight in healthy subjects and people with type 1 and type 2 diabetes mellitus, J Clin Endocrinol Metab, 88 (2003) 2706-2713.

[253] S. Dalle, R. Burcelin, P. Gourdy, Specific actions of GLP-1 receptor agonists and DPP4 inhibitors for the treatment of pancreatic beta-cell impairments in type 2 diabetes, Cellular signalling, 25 (2013) 570-579.

[254] E.J. Verspohl, Novel therapeutics for type 2 diabetes: incretin hormone mimetics (glucagon-like peptide-1 receptor agonists) and dipeptidyl peptidase-4 inhibitors, Pharmacol Ther, 124 (2009) 113138.

[255] M.L. Mohler, Y. He, Z. Wu, D.J. Hwang, D.D. Miller, Recent and emerging anti-diabetes targets, Medicinal research reviews, 29 (2009) 125-195.

[256] T. Jose, S.E. Inzucchi, Cardiovascular effects of the DPP-4 inhibitors, Diabetes \& vascular disease research : official journal of the International Society of Diabetes and Vascular Disease, 9 (2012) 109116.

[257] A.H. Barnett, The role of GLP-1 mimetics and basal insulin analogues in type 2 diabetes mellitus: guidance from studies of liraglutide, Diabetes Obes Metab, 14 (2012) 304-314. 
[258] A. Shiraki, J. Oyama, H. Komoda, M. Asaka, A. Komatsu, M. Sakuma, K. Kodama, Y. Sakamoto, N. Kotooka, T. Hirase, K. Node, The glucagon-like peptide 1 analog liraglutide reduces TNF-alphainduced oxidative stress and inflammation in endothelial cells, Atherosclerosis, 221 (2012) 375-382.

[259] E.L. Raab, P.M. Vuguin, D.A. Stoffers, R.A. Simmons, Neonatal exendin-4 treatment reduces oxidative stress and prevents hepatic insulin resistance in intrauterine growth-retarded rats, American journal of physiology. Regulatory, integrative and comparative physiology, 297 (2009) R1785-1794.

[260] M.C. Bunck, A. Corner, B. Eliasson, R.J. Heine, R.M. Shaginian, Y. Wu, P. Yan, U. Smith, H. YkiJarvinen, M. Diamant, M.R. Taskinen, One-year treatment with exenatide vs. insulin glargine: effects on postprandial glycemia, lipid profiles, and oxidative stress, Atherosclerosis, 212 (2010) 223-229.

[261] K. Chiba, K. Adachi, Discovery of fingolimod, the sphingosine 1-phosphate receptor modulator and its application for the therapy of multiple sclerosis, Future medicinal chemistry, 4 (2012) 771781.

[262] M. van Eijk, J. Aten, N. Bijl, R. Ottenhoff, C.P. van Roomen, P.F. Dubbelhuis, I. Seeman, K. Ghauharali-van der Vlugt, H.S. Overkleeft, C. Arbeeny, A.K. Groen, J.M. Aerts, Reducing glycosphingolipid content in adipose tissue of obese mice restores insulin sensitivity, adipogenesis and reduces inflammation, PloS one, 4 (2009) e4723.

[263] J.R. Ussher, T.R. Koves, V.J. Cadete, L. Zhang, J.S. Jaswal, S.J. Swyrd, D.G. Lopaschuk, S.D. Proctor, W. Keung, D.M. Muoio, G.D. Lopaschuk, Inhibition of de novo ceramide synthesis reverses diet-induced insulin resistance and enhances whole-body oxygen consumption, Diabetes, 59 (2010) 2453-2464.

[264] A. Ceriello, Hypothesis: the "metabolic memory", the new challenge of diabetes, Diabetes research and clinical practice, 86 Suppl 1 (2009) S2-6.

[265] S.H. Han, Y.H. Kim, I. Mook-Jung, RAGE: the beneficial and deleterious effects by diverse mechanisms of actions, Molecules and cells, 31 (2011) 91-97.

[266] M.B. Manigrasso, J. Juranek, R. Ramasamy, A.M. Schmidt, Unlocking the biology of RAGE in diabetic microvascular complications, Trends in endocrinology and metabolism: TEM, 25 (2014) 1522.

[267] Y. Ishibashi, T. Matsui, M. Takeuchi, S. Yamagishi, Metformin inhibits advanced glycation end products (AGEs)-induced renal tubular cell injury by suppressing reactive oxygen species generation via reducing receptor for AGEs (RAGE) expression, Hormone and metabolic research $=$ Hormon- und Stoffwechselforschung $=$ Hormones et metabolisme, 44 (2012) 891-895. 
Table 1: ANTIOXIDANT STRATEGIES TO CONTROL OXIDATIVE STRESS IN DIABETES

$\underline{\text { Enzymatic antioxidants }}$

SOD / Catalases / GXP mimetics

SOD mimetics: metaloporphyrins, tempol

Cationic meso Mn(III)-N-substituted pyridylporphyrins, N,N'-disubstituted imidazolylporphyrins (MnPs)

Mito Q10

Catalases mimetics

Salen-manganese complex

GXP mimetics:

Ebselen: 2-phenyl-1,2-benzisoselenazol-3(2H)-one

Diphenyl diselenide (DPDS)

$\underline{\text { Antioxidant vitamins }}$

Vitamin C (ascorbic acid)

Vitamin E (tocopherols), trolox (an analog of alpha-tocopherol)

Folic acid (vitamin B9)

$\underline{\text { Non-vitamin antioxidants }}$

$\mathrm{N}$-acetylcysteine

Lipoic acid: alpha-lipoic acid

Coenzyme Q10

Mitochondria-targeted antioxidants: MitoQ, XJB-5-131, SS31 
Sequestration of ions: Lazaroids: 21-aminosteroids, U75412E, tirilazad mesylate

Xanthine oxido-reductase inhibitors: allopurinol and its metabolite: oxypurinol

$\underline{\text { Drugs with antioxidant properties }}$

$\underline{\text { Classical agents }}$

Metformin: 1,1-Dimethylbiguanide

Glibenclamide: 1-[4-[2-(5-Chloro-2-methoxybenzamido)ethyl]phenylsulfonyl]-3cyclohexylurea

Therapeutic approaches with new agents

Edaravone: 3-Methyl-1-phenyl-2-pyrazolin-5-one

Benfotiamine: S-[2-\{[(4-amino-2-methylpyrimidin-5-yl)methyl] (formyl)amino $\}-5-$

(phosphonooxy)pent- 2-en-3-yl] benzenecarbothioate

Poly(ADP-ribose) polymerase inhibitors (PARP inhibitors)

Classical PARP inhibitors: nicotinamide and its 5-methyl derivates; benzamide (3aminobenzamide: 3-AB; 3-methoxybenzamide)

Newer PARP inhibitors: dihydroisoquinolinones, isoquinolinones, Zinc finger PARP inhibitors: 6-nitroso 1,2-benzopyrone,3,3-nitrosobenzamide and iodo-nitro-benzamide (INO2BA)

\section{Peroxynitrite decomposition catalysts}

FP-15: FeIIItetrakis-2-(triethylene glycol monomethyl ether)pyridyl porphyrin FeTTPS, FeTMPs

$\underline{\text { Other pharmacological approaches }}$ 
Angiotensin-converting enzyme inhibitors (ACEI)

Peroxisome proliferator-activated receptors (PPARs):

Thiazolidinediones (glitazones): troglitazone, pioglitazone, rosiglitazone

\section{$\underline{\text { Promizing new clinical agents }}$}

FGF21: fibroblast growth factor 21

Epoxide hydrolase inhibitors: sorafenib (N-[4-Chloro-3-(trifluoromethyl)phenyl]-N'-[4-[2-(Nmethylcarbamoyl)-4-pyridyloxy]phenyl]urea ) and derivates

Incretin mimetics and inhibitors of their metabolism

Glucagon-like peptide-1 (GLP-1) receptors agonists: exenatide, exendin-4, liraglutide,

Dipeptidyl Peptidase -4 (DPP-4) inhibitors: sitagliptin, saxagliptin, linagliptin, vildagliptin, alogliptin

$\underline{\text { Inhibitors of ceramide synthesis or activators of ceramide degradation and sphingosine }}$ $\underline{\text { modulators }}$

S1P1,3,4,5 R agonist: Fingolimod (2-amino-2-2-(4-octylphenyl)ethyl) propane-1,3-diol hydrochloride) (FTY720)

S1P1R-specific agonist: (2-amino-2-\{3-[4-(3-benzyloxy-phenylsulfanyl)-2-chloro-phenyl]ethyl\}-propan-1,3 diol hydrochloride): KRP203: 


\section{Figure Legends}

Figure 1: Schematic representation of glucose metabolism and oxidative stress coupled to three major pathways: polyol, diacyglycerol and AGE

Radicals derived from oxygen: $\mathrm{O}_{2}{ }^{\bullet-}$, superoxide; ${ }^{\bullet} \mathrm{OH}$, hydroxyl; nitric oxide: ${ }^{\bullet} \mathrm{NO}$. Main antioxidant enzymes: CAT, catalase; Cu-SOD, copper SOD; Mn-SOD, manganese SOD; GPx, glutathione peroxidase; GR, glutathione reductase; GSH, glutathione; GSSG, GSH disulfide; $\mathrm{H}_{2} \mathrm{O}_{2}$, hydrogen peroxide; $\mathrm{HO}-1$, heme oxygenase-1; $\mathrm{NAD}(\mathrm{P}) \mathrm{H}$, nicotinamide adenine dinucleotide phosphate; eNOS: endothelial nitric oxide synthase; iNOS: inducible nitric oxide synthase; peroxynitrite: $\mathrm{ONOO}^{-} / \mathrm{ONOOH}$ : Trx, thioredoxin; Prx, peroxiredoxin.

Figure 2: The molecular basis of the diabetic process.

Intracellular high-glucose metabolism is associated with mitochondrial Reactive Oxygen Species and oxidative stress. PARP modifies GAPDH, thereby reducing its activity. Decreased GAPDH activity increases glycolytic intermediates that, in turn, activate the polyol pathway, increase intracellular AGEs and DAG formation, activate PKC and subsequently NF- $\kappa \mathrm{B}$. These metabolic pathways elicit alterations in gene expression, inflammatory responses (activated neutrophils), and structural changes in cellular constituents.

Figure 3: Diagram showing elements of the unifying mechanism of hyperglycemia-induced cellular damage and adaptative response to oxidative and electrophile stress.

ROS, RNS and endogenous and exogenous electrophiles/ activators (see text for more details) can alter the AP-1, HSF1, NF- $\kappa \mathrm{B} / \mathrm{I} \kappa \mathrm{B}, \mathrm{Nrf} 2-\mathrm{Keap} 1$ and Bach-1 signaling complexes. Subsequent nuclear translocation and the induction of antioxidant response element (ARE)driven genes result in upregulated environmental stress reponse and cell survival. 
Figure 4: Anti-diabetes targets: pharmacological options (shaded parts) to modulate the oxidative stress with classical agents and new agents. This schema presents the sources and consequences of the production of nitric oxide (NO)) and reactive oxygen species in intracellular and extracellular compartments in diabetes. (see the details in the text). 


\section{Introduction}

\section{Free radicals and antioxidants (Figure 1)}

\section{Metabolic stress and diabetes (Figure 2)}

3.1. Oxidative and nitroxidative stress

3.2. Intracellular signaling (Figure 3)

3.2.1. FOXO

3.2.2. $N R F 2$

3.2.3. $A P-1$

3.2.4. $N F-\square B$

3.2.5. PPARS

3.2.6. Bach1

3.2.7. Other transcription factors implicated in oxidative stress regulation and diabetes

3.3. Electrophile stress (Figure: 3 )

3.4. Sphingolipid signaling

\section{Insulin resistance and oxidative stress}

4.1. Pancreas, insulin resistance and oxidative stress:

4.2. Adipose and skeletal tissue, insulin resistance and oxidative stress:

4.3.Liver, insulin resistance and oxidative stress

\section{Antioxidant strategies to control oxidative stress in diabetes}

5.1.Enzymatic antioxidants

5.2. Non enzymatic antioxidants

5.2.1. Antioxidant vitamins

Vitamin C 
Vitamin E

Folic acid

5.2.2. Non-vitaminic antioxidants

$N$-Acetylcysteine

Lipoic acid

Coenzyme $Q 10$

Mitochondria-targeted antioxidants: MitoQ, XJB-5-131, SS31

5.2.3. Sequestration of metal ions such as iron

5.2.4. Physiological approach: exercise

5.3. Therapeutic approaches with classical agents:

5.4. Therapeutic approaches with new agents (Figure 4)

\subsubsection{Edaravone}

5.4.2. Benfotiamine

5.4.3. Poly(ADP-ribose) polymerase inhibitors (PARP inhibitors)

5.4.4. Peroxynitrite decomposition catalysts

5.5. Other pharmacological approachs

5.5.1. Angiotensin-converting enzyme inhibitors (ACEI)

5.5.2. Peroxisome proliferator-activated receptors (PPARs) such as thiazolidinediones

5.6. Promising new clinical agents:

\subsection{1. $F G F 21$}

5.6.2. Epoxide hydrolase inhibitors

5.6.3. Incretin mimetics and inhibitors of their metabolism

5.6.4. Inhibitors of ceramide synthesis or activators of ceramide degradation and sphingosine modulators

5.6.5. P66Shc: a key effector and possible target 
6. Conclusions 